\title{
Refined Estimates on Conjectures of Woods and Minkowski-I \\ Kathuria $L^{*}$ and Raka M \\ Centre for Advanced Study in Mathematics, Panjab University, Chandigarh-160014, India
}

\begin{abstract}
Let ${ }^{\wedge}$ be a lattice in $R^{n}$ reduced in the sense of Korkine and Zolotare having a basis of the form $\left(A_{1}, 0,0, \ldots, 0\right)$, $\left(a_{2,1} A_{2}, \ldots, 0\right), \ldots,\left(a_{n, 1}, a_{n, 2}, \ldots, a_{n, n-1}, A_{n}\right)$ where $A_{1}, A_{2}, \ldots$, An are all positive. A well known onjecture of Woods in Geometry of Numbers asserts that if $\mathrm{A}_{1} \mathrm{~A}_{2} \ldots \mathrm{A}_{\mathrm{n}=1}$ and $\mathrm{A}_{i} \leq A_{1}$ for each $\mathrm{i}$ then any closed sphere in $\mathrm{R}^{\mathrm{n}}$ of radius $\sqrt{n / 2}$ contains a point of ${ }^{\wedge}$. Woods' Conjecture is known to be true for $n \leq 9$. In this paper we obtain estimates on the Conjecture of Woods for $n=10 ; 11$ and 12 improving the earlier best known results of Hans-Gill et al. These lead to an improvement, for these values of $n$, to the estimates on the long standing classical conjecture of Minkowski on the product of $\mathrm{n}$ non-homogeneous linear forms.
\end{abstract}

MSC: 11H46; 11 - 04; 11J20; 11J37; 52C15.

Keywords: Lattice; Covering; Non-homogeneous; Product of linear forms; Critical determinant; Korkine and Zolotare reduction; Hermite's constant; Centre density

\section{Introduction}

Let $\mathrm{L}_{\mathrm{i}}=\mathrm{a}_{\mathrm{il}} \mathrm{x}_{1}+\ldots .+\mathrm{a}_{\mathrm{in}} \mathrm{x}_{\mathrm{n}} ; 1 \leq i \leq n$ be $\mathrm{n}$ real linear forms in $\mathrm{n}$ variables $\mathrm{x} 1 ;::: ; \mathrm{xn}$ and having determinant $\Delta=\operatorname{det}\left(\mathrm{a}_{\mathrm{ij}}\right) \neq 0$ The following conjecture is attributed to $\mathrm{H}$. Minkowski:

Conjecture I: For any given real numbers $c 1 ;::: ; \mathrm{cn}$, there exists integers $\mathrm{x} 1 ;::$ : ; xn such that

$$
\left|\left(\mathrm{L}_{1}+\mathrm{c}_{1}\right) \ldots\left(\mathrm{L}_{\mathrm{n}}+\mathrm{c}_{\mathrm{n}}\right)\right| \leq \frac{1}{2 n}|\Delta|
$$

Equality is necessary if and only if after a suitable unimodular transformation the linear forms $\mathrm{L}_{\mathrm{i}}$ have the form $2 c_{i} x_{l}$ for $1 \leq i \leq n$

This result is known to be true for $n \leq 9$ For a detailed history and the related results,

Minkowski's Conjecture is equivalent to saying that [1]

$$
M_{n} \leq \frac{1}{2 n}|\Delta|
$$

where $M_{n}=M_{n}(\Delta)$ is given by

$$
M_{n}=\operatorname{Sup}_{L_{1}, \ldots, L_{n}\left(\mathrm{c}_{1}, \ldots, \mathrm{c}_{\mathrm{n}}\right) \in \mathrm{R}^{\mathrm{n}}} \operatorname{Iuf}_{\left(\mathrm{u}_{1}, \ldots, \mathrm{u}_{\mathrm{n}}\right) \in \mathrm{Z}^{\mathrm{n}}} \prod_{i=1}^{n}\left|L_{i}\left(\mathrm{u}_{1}, \ldots ., \mathrm{u}_{\mathrm{n}}\right)+\mathrm{c}_{\mathrm{i}}\right|
$$

Chebotarev proved the weaker inequality

$$
M_{n} \leq \frac{1}{2^{n / 2}}|\Delta|
$$

Since then several authors have tried to improve upon this estimate. The bounds have been obtained in the form

$$
M_{n} \leq \frac{1}{v_{n} 2^{n / 2}}|\Delta|
$$

where $\mathrm{Vn}>1$. Clearly $v_{n} \leq 2^{n / 2}$ by considering the linear forms $\mathrm{Li}=\mathrm{xi}$ and $c_{i}=\frac{1}{2}$ for $1 \leq i \leq n$ During 1949-1986, many authors such as Davenport, Woods, Bombieri, Gruber, Skubenko, Andrijasjan, Il'in and Malyshev obtained $\mathrm{V}_{\mathrm{n}}$ for large $\mathrm{n}$. obtained $v_{n}=4-2(2-3 \sqrt{2 / 4})^{\mathrm{n}}-2^{-n / 2}$ for all $\mathrm{n}$ [2-4] improved Mordell's estimates for $6 \leq n \leq 31$ Hans-Gill et al. $[12,14]$ got improvements on the results of [5-8] for $9 \leq n \leq 31$ Since recently $\mathrm{V}_{n} 9=2^{9 / 2}$ has been established by the authors [9], we study $\mathrm{Vn}$ for $10 \leq n \leq 33$ in a series of three papers.
In this paper we obtain improved estimates on Minkowski's Conjecture for $n=10 ; 11$ and 12. In next papers [10-12], we shall derive improved estimates on Minkowski's Conjecture for $n=13 ; 14 ; 15$ and for $16 \leq n \leq 33$ respectively [13-16]. For sake of comparison, we give results by our improved $\mathrm{Vn}$ in Table 1 .

We shall follow the Remak-Davenport approach. For the sake of convenience of the reader we give some basic results of this approach. Minkowski's Conjecture can be restated in the terminology of lattices as : Any lattice $\wedge$ of determinant $d(\wedge)$ in $\mathrm{Rn}$ is a covering lattice for the set

$$
S:\left|\mathrm{x}_{1} \mathrm{x}_{2} \ldots . \mathrm{x}_{\mathrm{n}}\right| \leq \frac{d(\wedge)}{2^{n}}
$$

The weaker result (1.3) is equivalent to saying that any lattice $\wedge$ of determinant $d(\wedge)$ in $\mathrm{Rn}$ is a covering lattice for the set

$$
S:\left|\mathrm{x}_{1} \mathrm{x}_{2} \ldots . \mathrm{x}_{\mathrm{n}}\right| \leq \frac{d(\wedge)}{v_{n} 2^{n / 2}}
$$

Define the homogeneous minimum of $\wedge$ as

$$
m_{H}(\wedge)=\inf \left\{\left|\mathrm{x}_{1} \mathrm{x}_{2} \ldots . \mathrm{x}_{\mathrm{n}}\right|: \mathrm{X}=\left(\mathrm{x}_{1}, \mathrm{x}_{2}, \ldots \mathrm{x}_{\mathrm{n}}\right) \in \wedge, \mathrm{X} \neq o\right\}
$$

Proposition 1. Suppose that Minkowski Conjecture has been proved for dimensions $1,2, \ldots, \mathrm{n}-1$ : Then it holds for all lattices $\wedge$ in $\mathrm{Rn}$ for which $\mathrm{MH}(\wedge)=0$.

Proposition 2. If $\wedge$ is a lattice in $\mathrm{Rn}$ for $n \geq 3$ with $\mathrm{MH}(\wedge) \neq 0$ then there exists an ellipsoid having $n$ linearly independent points of $\wedge$ on its boundary and no point of $\wedge$ other than $\mathrm{O}$ in its interior.

It is well known that using these results, Minkowski's Conjecture would follow from

*Corresponding author: Kathuria L, Centre for Advanced Study in Mathematics Panjab University, Chandigarh-160014, India, Tel: 08754216121; E-mail kathurialeetika@gmail.com

Received February 10, 2015; Accepted March 23, 2015; Published April 15, 2015 Citation: Kathuria L, Raka M (2015) Refined Estimates on Conjectures of Woods and Minkowski-I. J Appl Computat Math 4: 209. doi:10.4172/2168-9679.1000209

Copyright: $\odot 2015$ Kathuria L, et al. This is an open-access article distributed unde the terms of the Creative Commons Attribution License, which permits unrestricted use, distribution, and reproduction in any medium, provided the original author and source are credited. 
Citation: Kathuria L, Raka M (2015) Refined Estimates on Conjectures of Woods and Minkowski-I. J Appl Computat Math 4: 209. doi:10.4172/21689679.1000209

Page 2 of 10

\begin{tabular}{|c|c|c|c|c|}
\hline & Estimates by Mordell & Estimates by II'in & Estimates by Hans-Gill et al & Our improved Estimates \\
\hline $\mathrm{n}$ & $V_{n}$ & $V_{n}$ & $V_{n}$ & $V_{n}$ \\
\hline 10 & 2.899061 & 3.47989 & 24.3627506 & 27.60348 \\
\hline 11 & 2.973102 & 3.52291 & 29.2801145 & 33.47272 \\
\hline 12 & 3.040525 & 3.55024 & 32.2801213 & 39.59199 \\
\hline 13 & 3.102356 & 3.57856 & 34.8475153 & 45.40041 \\
\hline 14 & 3.159373 & 3.60209 & 37.8038391 & 51.26239 \\
\hline 15 & 3.21218 & 3.61116 & 40.905198 & 57.00375 \\
\hline 16 & 3.261252 & 3.61908 & 44.3414913 & 57.4702 \\
\hline 17 & 3.306972 & 3.63924 & 47.2339309 & 57.67598 \\
\hline 18 & 3.349652 & 3.66176 & 46.7645724 & 57.38876 \\
\hline 19 & 3.389556 & 3.66734 & 47.2575897 & 60.09339 \\
\hline 20 & 3.426907 & 3.67236 & 46.8640155 & 58.48592 \\
\hline 21 & 3.461897 & 3.67692 & 46.0522028 & 56.42571 \\
\hline 22 & 3.494699 & 3.68408 & 43.6612034 & 53.94142 \\
\hline 23 & 3.525464 & 3.68633 & 37.8802374 & 50.98842 \\
\hline 24 & 3.55433 & 3.68978 & 32.5852958 & 47.74632 \\
\hline 25 & 3.581421 & 3.69295 & 27.8149432 & 42.39088 \\
\hline 26 & 3.606852 & 3.69589 & 23.0801951 & 38.8657 \\
\hline 27 & 3.630729 & 3.70012 & 17.3895105 & 31.93316 \\
\hline 28 & 3.653149 & 3.70263 & 12.9938763 & 26.10663 \\
\hline 29 & 3.674203 & 3.70497 & 9.5796191 & 19.96254 \\
\hline 30 & 3.693976 & 3.70867 & 6.7664335 & 16.06884 \\
\hline 31 & 3.712547 & 3.72558 & 4.745972 & 11.23872 \\
\hline 32 & 3.729989 & & & 8.325879 \\
\hline 33 & 3.746371 & & & 5.411488 \\
\hline
\end{tabular}

Table 1: The weaker result.

Conjecture II. If $\wedge$ is a lattice in $\mathrm{Rn}$ of determinant 1 and there is a sphere $|\mathrm{X}|<\mathrm{R}$ which contains no point of $\wedge$ other than $\mathrm{O}$ in its interior and has $n$ linearly independent points of $\wedge$ on its boundary then $\wedge$ is a covering lattice for the closed sphere of radius $\sqrt{n / 4}$ Equivalently, every closed sphere of radius $\sqrt{n / 4}$ lying in Rn contains a point of $\wedge$.

They formulated a conjecture from which Conjecture-II follows immediately. To state Woods' conjecture, we need to introduce some terminology $[17,18]$.

Let $\mathrm{L}$ be a lattice in $\mathrm{Rn}$. By the reduction theory of quadratic forms introduced by a cartesian co-ordinate system may be chosen in $\mathrm{Rn}$ in such a way that $L$ has a basis of the form [19-22],

$$
\left(\mathrm{A}_{1} ; 0 ; 0 ;::: ; 0\right) ;\left(\mathrm{a}_{2 ; 1} ; \mathrm{A}_{2} ; 0 ;::: ; 0\right) ;::: ;\left(\mathrm{a}_{\mathrm{n} ; 1} ; \mathrm{a}_{\mathrm{n} ; 2} ;::: ; \mathrm{a}_{\mathrm{n} ; \mathrm{n}-1}, \mathrm{~A}_{\mathrm{n}}\right)
$$

where $\mathrm{A} 1 ; \mathrm{A} 2 ;:: ;$; An are all positive and further for each $\mathrm{i}=1 ; 2 ;::: ; \mathrm{n}$ any two points of the lattice in $\mathrm{R}^{\mathrm{n}-\mathrm{i}+1}$ with basis

$$
\left(A_{i} ; 0 ; 0 ;::: ; 0\right) ;\left(a_{i+1 ; i} ; A_{i+1} ; 0 ;::: ; 0\right) ;::: ;\left(a_{n ; i} ; a_{n ; i+1} ;::: ; a_{n ; n-1} ; A_{n}\right)
$$

are at a distance atleast $\mathrm{Ai}$ apart. Such a basis of $\mathrm{L}$ is called a reduced basis [23].

Conjecture III (Woods): If $\mathrm{A}_{1} \mathrm{~A}_{2} \ldots \mathrm{A}_{\mathrm{n}}=1$ and $A_{i} \leq A_{1}$ for each $\mathrm{i}$ then any closed sphere in Rn of radius $\sqrt{n / 2}$ contains a point of $\mathrm{L}$.

Woods [10] proved this conjecture for $4 \leq n \leq 6$ Hans-Gill et al. [12] gave a unified proof of Woods' Conjecture for $n \leq 6$ Hans-Gill et al. [12,14] proved Woods' Conjecture for $n=7$ and $n=8$ and thus completed the proof of Minkowski's Conjecture for $\mathrm{n}=7$ and 8 Woods $[10,24]$ proved Conjecture and hence Minkowski's Conjecture for $n=9$. With the assumptions as in Conjecture III, a weaker result would be that
If $w_{n} \geq n$ any closed sphere in $\mathrm{R}^{\mathrm{n}}$ of radius $\sqrt{w_{n} / 2}$ contains a point of $L[25,26]$.

Hans-Gill et al. [12,14] obtained the estimates $\mathrm{w}_{\mathrm{n}}$ on Woods' Conjecture for $n^{3} \geq 9 \quad \mathrm{As}_{9}=9$ has been established by the authors [17] recently, we study $\mathrm{w}_{\mathrm{n}}$ for $n^{3} \geq 10$ in a series of three papers. In this paper we obtain improved estimates $\mathrm{w}_{\mathrm{n}}$ on Woods' Conjecture for $\mathrm{n}=10 ; 11$ and 12. In next papers $[18,19]$, we shall derive improved estimates $\mathrm{w}_{\mathrm{n}}$ on Woods' Conjecture for $\mathrm{n}=13 ; 14 ; 15$ and for $16 \leq n \leq 33$ respectively. Together with the following result of Hans-Gill et al. [12], we get improvements of $\mathrm{w}_{\mathrm{n}}$ for $n^{3} \geq 34$ also.

Proposition 3. Let $\mathrm{L}$ be a lattice in $\mathrm{R}^{\mathrm{n}}$ with $\mathrm{A}_{1} \mathrm{~A}_{2} \ldots \mathrm{A}_{\mathrm{n}}=1$ and $A_{i} \leq A_{1}$ for each i. Let $0<1_{\mathrm{n}} \leq A_{n}^{2} \leq m_{n}$ where $\mathrm{l}_{\mathrm{n}}$ and $\mathrm{m}_{\mathrm{n}}$ are real numbers. Then $\mathrm{L}$ is a covering lattice for the sphere $|\mathrm{x}| \leq \sqrt{w_{n} / 2}$ where $\mathrm{Wn}$ is defined inductively by

$$
w_{n}=\max \left\{\mathrm{w}_{\mathrm{n}-1} 1_{n}^{-1 / 1_{\mathrm{n}-1}}+\mathrm{1}_{\mathrm{n}}, \mathrm{w}_{\mathrm{n}-1} \mathrm{~m}_{n}^{-1 / m_{n-1}}+\mathrm{m}_{\mathrm{n}}\right\}
$$

Here we prove

Theorem 1. Let $\mathrm{n}=10 ; 11 ; 12$. If $\mathrm{d}(\mathrm{L})=\mathrm{A} 1::: \mathrm{An}=1$ and $A_{i} \leq A_{1}$ for $\mathrm{i}=2 ; \ldots ; \mathrm{n}$, then any closed sphere in $\mathrm{Rn}$ of radius $\sqrt{w_{n}} / 2$ contains a point of $\mathrm{L}$, where $w_{10}=10.3, w_{11}=11.62$ and $w_{12}=13$.

The earlier best known values were $\mathrm{w}_{10}=10: 5605061, \mathrm{w}_{11}=11: 9061976$ and $\mathrm{w}_{12}=13: 4499927$.

To deduce the results on the estimates of Minkowski's Conjecture we also need the following generalization of Proposition 1

Proposition 4. Suppose that we know

$$
M_{j} \leq \frac{1}{v_{j} 2^{j / 2}|\Delta|} \text { for } 1 \leq j \leq n-1
$$


Let $\mathrm{v}_{\mathrm{n}}<\min \mathrm{V}_{\mathrm{k} 1} \mathrm{~V}_{\mathrm{k} 2} \ldots \mathrm{V}_{\mathrm{ks}}$, where the minimum is taken over all $\left(\mathrm{k}_{1} ; \mathrm{k}_{2} ; \quad ; \mathrm{k}_{\mathrm{s}}\right)$ such that $\mathrm{n}=\mathrm{k} 1+\mathrm{k} 2+:::+\mathrm{ks}$, ki positive integers for all $\mathrm{i}$ and $s^{3} \geq 2$. Then for all lattices in Rn with homogeneous minimum $\mathrm{MH}(<)=0$, the estimate $\mathrm{V}_{\mathrm{n}}$ holds for Minkowski's Conjecture.

Since by arithmetic-geometric inequality the sphere $\left\{\mathrm{X} \in \mathrm{R}^{\mathrm{n}}:|\mathrm{X}| \leq \frac{\sqrt{w_{n}}}{2}\right\}$ is a subset of $\left\{\mathrm{X}:\left|\mathrm{x}_{1} \mathrm{X}_{2} \ldots \mathrm{x}_{\mathrm{n}}\right| \leq \frac{1}{2^{n / 2}}\left(\frac{w_{n}}{2_{n}}\right)^{\mathrm{n} / 2}\right\}$ Propositions 2 and 4 immediately imply

Theorem 2: The values of Vn for the estimates of Minkowski's Conjecture can be taken as $\left(\frac{2 n}{w_{n}}\right)^{n / 2}$

For $10 \leq n \leq 33$ these values are listed in Table 1. In Section 2 we state some preliminary results and in Sections 3-5 we prove Theorem 1 for $\mathrm{n}=10 ; 11$ and 12 .

\section{Preliminary Results and Plan of the Proof}

Let $\mathrm{L}$ be a lattice in $\mathrm{Rn}$ reduced in the sense of Korkine and Zolotare. Let $(\mathrm{Sn})$ denotes the critical determinant of the unit sphere $\Delta \mathrm{Sn}$ with centre $\mathrm{O}$ in $\mathrm{R}^{\mathrm{n}}$ i.e.

$\Delta\left(\mathrm{S}_{\mathrm{n}}\right)=\operatorname{Inf}\left\{\mathrm{d}(\wedge): \wedge\right.$ has no point other than $\mathrm{O}$ in the interior of $\left.\mathrm{S}_{\mathrm{n}}\right\}$

Let $\gamma_{n}$ be the Hermite's constant i.e. $\gamma_{n}$ is the smallest real number such that for any positive de nite quadratic form $\mathrm{Q}$ in $\mathrm{n}$ variables of determinant $D$, there exist integers $u_{1} ; u_{2} ; \ldots ; u_{n}$ not all zero satisfying

$$
Q\left(\mathrm{u}_{1}, \mathrm{u}_{2}, \ldots \mathrm{u}_{\mathrm{n}}\right) \leq \gamma_{\mathrm{n}} D^{1 / n}
$$

It is well known that We write $\mathrm{A}_{\mathrm{i}}^{2}=\mathrm{Bi}$.

We state below some preliminary lemmas. Lemmas 1 and 2 are due to Woods [25], Lemma 3 is due to Korkine and Zolotare [21] and Lemma 4 is due to Pendavingh and Van Zwam [24]. In Lemma 5, the cases $\mathrm{n}=2$ and 3 are classical results of Lagrange and Gauss; $\mathrm{n}=4$ and 5 are due to Korkine and Zolotare [21] while $n=6 ; 7$ and 8 are due to Blichfeldt [3].

Lemma 1. If $2 \Delta\left(\mathrm{S}_{\mathrm{n}+1}\right) \mathrm{A}_{1}^{n} \geq d(1)$ then any closed sphere of radius

$$
R=A_{1}\left(1-\left\{\mathrm{A}_{1}^{n} \Delta\left(\mathrm{S}_{\mathrm{n}+1}\right) / \mathrm{d}(\mathrm{L})\right\}^{2}\right)^{1 / 2}
$$

in $\mathrm{R}^{\mathrm{n}}$ contains a point of $\mathrm{L}$.

Lemma 2. For a Fixed integer i with $1 \leq i \leq n-1$ denote by $\mathrm{L}_{1}$ the lattice in $\mathrm{R}^{\mathrm{i}}$ with reduced basis

$$
\left(\mathrm{A}_{1}, 0, \ldots, 0\right),\left(\mathrm{a}_{2,1}, \mathrm{~A}_{2}, 0, \ldots, 0\right), \ldots,\left(\mathrm{a}_{\mathrm{i}, 1}, \mathrm{a}_{\mathrm{i}, 2}, \ldots, \mathrm{a}_{\mathrm{i}, \mathrm{i}-1}, \mathrm{~A}_{\mathrm{i}}\right)
$$

and denote by $\mathrm{L} 2$ the lattice in $\mathrm{R}^{\mathrm{n}-\mathrm{i}}$ with reduced basis

$$
\left(\mathrm{A}_{\mathrm{i}+1} ; 0 ; \quad ; 0\right) ;\left(\mathrm{a}_{\mathrm{i}+2 ; i+1} ; \mathrm{A}_{\mathrm{i}+2} ; 0 ; \quad ; 0\right) ; \quad ;\left(\mathrm{a}_{\mathrm{n}, \mathrm{i}+1} ; \mathrm{a}_{\mathrm{n} ; \mathrm{i}+2} ; \quad ; \mathrm{a}_{\mathrm{n} ; \mathrm{n}-1} ; \mathrm{A}_{\mathrm{n}}\right) .
$$

If any closed sphere in $\mathrm{R}_{\mathrm{i}}$ of radius $\mathrm{r} 1$ contains a point of $\mathrm{L}_{1}$ and if any closed sphere in $\mathrm{R}_{\mathrm{n} \text { - }}$ of radius $\mathrm{r}_{2}$ contains a point of $\mathrm{L}_{2}$ then any closed sphere in $\mathrm{Rn}$ of radius $\left(\mathrm{r}_{1}^{2}+r_{2}^{2}\right)^{1 / 2}$ contains a point of $\mathrm{L}$ :

Lemma 3. For all relevant $i$,

$$
B_{i+1} \geq \frac{3}{4} B_{i} \text { and } B_{i+2} \geq \frac{2}{3} B_{i}
$$

Lemma 4. For all relevant $i$,

$$
B_{i+4} \geq(0.46873) \mathrm{B}_{\mathrm{i}}
$$

\section{Throughout the paper we shall denote 0.46873 by $\varepsilon$.}

Lemma 5. $\Delta\left(\mathrm{S}_{\mathrm{n}}\right)=\sqrt{3 / 2}, 1 / \sqrt{2}, 1 / 2 \sqrt{2}, \sqrt{3 / 8}, 1 / 8$ and $1 / 16$ for $\mathrm{n}=2 ; 3 ; 4 ;$ $5 ; 6 ; 7$ and 8 respectively:

Lemma 6. For any integer $s ; 1 \leq s \leq n-1$

$$
\begin{aligned}
& B_{1} B_{2} \ldots B_{s-1} B_{s}^{n-s+1} \leq \gamma_{n-s+1}^{n-s+1} \quad \text { and } \\
& B_{1} B_{2} \ldots B_{s} \leq\left(\gamma_{n}^{\frac{1}{n-1}} \gamma_{n-1}^{\frac{1}{n-2}} \ldots \gamma_{n-s+1}^{\frac{1}{n-s}}\right)^{\mathrm{n}-\mathrm{s}}
\end{aligned}
$$

This is Lemma 4 of Hans-Gill et al. [12].

Lemma 7.

$$
\left\{(8.5337)^{\frac{1}{5}} \gamma_{n}^{\frac{1}{n-1}} \gamma_{n-1}^{\frac{1}{n-2}} \cdots \gamma_{6}^{\frac{1}{5}}\right\}^{-1} \leq B_{n} \leq \gamma_{n-1}^{\frac{n-1}{n}}
$$

This is Lemma 6 of Hans-Gill et al. [14].

Remark 1. Let

$\delta_{n}=$ the best centre density of packings of unit spheres in $\mathrm{R}^{\mathrm{n}}$;

$\delta_{n}^{*}=$ the best centre density of lattice packings of unit spheres in $\mathrm{R}^{\mathrm{n}}$ :

Then it is known that

$\gamma_{n}=4\left(\delta_{n}^{*}\right)^{\frac{2}{n}} \leq 4\left(\delta_{n}\right)^{\frac{2}{n}}$

$\delta_{n}^{*}$ and hence $\delta_{n}$ is known for $n \leq 8$ Also $\gamma_{24}=4$ has been proved by Cohn and Kumar [6]. For $9 \leq n \leq 12$ using the bounds on $\delta_{n}$ given by Cohn and Elkies [5] and inequality (2.6) we find that $\gamma_{9} \leq 2.1326324$, $\gamma_{10} \leq 2.2636302, \gamma_{11} \leq 2.3933470, \gamma_{12} \leq 2.5217871$

We assume that Theorem 1 is false and derive a contradiction. Let $\mathrm{L}$ be a lattice satisfying the hypothesis of the conjecture. Suppose that there exists a closed sphere of radius $\sqrt{w_{n} / 2}$ in $\mathrm{R}^{\mathrm{n}}$ that contains no point of $\mathrm{L}$ in $\mathrm{R}^{\mathrm{n}}$.

Since $B_{i}=A^{2}$ and $d(L)=1$; we have $B_{1} B_{2}::: B_{n}=1$ :

We give some examples of inequalities that arise. Let $\mathrm{L} 1$ be a lattice in R4 with basis $\left(\mathrm{A}_{1} ; 0 ; 0 ; 0\right),\left(\mathrm{a}_{2 ; 1} ; \mathrm{A}_{2} ; 0 ; 0\right) ;\left(\mathrm{a}_{3 ; 1} ; \mathrm{a}_{3 ; 2} ; \mathrm{A}_{3} ; 0\right) ;\left(\mathrm{a}_{4 ; 1} ; \mathrm{a}_{4 ; 2} ; \mathrm{a}_{4 ; 3} ; \mathrm{A}_{4}\right)$; and $\mathrm{L}_{\mathrm{i}}$ for $2 \leq i \leq n$ be lattices in $\mathrm{R} 1$ with basis $(\mathrm{Ai}+3)$. Applying Lemma 2 repeatedly and using Lemma 1 we see that if $2 \Delta\left(\mathrm{S}_{5}\right) \mathrm{A}_{1}^{4} \geq A_{1} A_{2} A_{3} A_{4}$ then any closed sphere of radius

$$
\left(\mathrm{A}_{1}^{2}-\frac{A_{1}^{10} \Delta\left(\mathrm{S}_{5}\right)^{2}}{A_{1}^{2} A_{2}^{2} A_{3}^{2} A_{4}^{2}}+\frac{1}{4} \mathrm{~A}_{5}^{2}+\ldots+\frac{1}{4} \mathrm{~A}_{n}^{2}\right)^{1 / 2}
$$

contains a point of L: By the initial hypothesis this radius exceeds $\sqrt{w_{n}} / 2$ Since $\Delta\left(\mathrm{S}_{5}\right)=1 / 2 \sqrt{2}$ and $B_{1} B_{2} \ldots . . B_{n}=1$ this results in the conditional inequality : if $B_{1}^{4} B_{5} B_{6} \ldots \mathrm{B}_{n} \geq 2$ then

$$
4 B_{1}-\frac{1}{2} B_{1}^{5} B_{5} B_{6} \ldots B_{n}+B_{5}+B_{6}+\ldots+B_{n}>w_{n}
$$

We call this inequality $(4 ; 1 ; \ldots ; 1)$; since it corresponds to the ordered partition $(4 ; 1 ; \ldots ; 1)$ of $\mathrm{n}$ for the purpose of applying Lemma 2 . Similarly the conditional inequality $(1 ; \ldots ; 1 ; 2 ; 1 ; \ldots ; 1)$ corresponding to the ordered partition $(1 ; \ldots ; 1 ; 2 ; 1 ; \ldots ; 1)$ is : if $2 B_{i} \geq B_{i+1}$ then

$$
B_{1}+\ldots+B_{i-1}+4 B_{i}-\frac{2 B_{i}^{2}}{B_{i+1}}+B_{i+2}+\ldots+B_{n}>w_{n}
$$

Since $4 B_{i}-\frac{2 B_{i}^{2}}{B_{i+1}} \leq 2 B_{i+1}$, (2.8) gives

$B_{1}+\ldots+B_{i-1}+2 B_{i+1}+B_{i+2}+\ldots+B_{n}>W_{n}:$ 
One may remark here that the condition $2 B_{i} \geq B_{i+1}$ is necessary only if we want to use inequality (2.8), but it is not necessary if we want to use the weaker inequality (2.9). This is so because if $2 \mathrm{~B}_{\mathrm{i}}<\mathrm{B}_{\mathrm{i}+1}$, using the partition $(1 ; 1)$ in place of $(2)$ for the relevant part, we get the upper bound $2 \mathrm{Bi}+\mathrm{B}_{\mathrm{i}+1}$ which is clearly less than $2 \mathrm{~B}_{\mathrm{i}+1}$. We shall call inequalities of type $(2.9)$ as weak inequalities and denote it by $(1 ; \ldots ; 1$; $2 ; 1 ; \ldots ; 1)_{w}$.

If $\left(\lambda_{1}, \lambda_{2}, \ldots, \lambda_{s}\right)$ is an ordered partition of $\mathrm{n}$, then the conditional inequality arising from it, by using Lemmas 1 and 2 , is also denoted by $\left(\lambda_{1}, \lambda_{2}, \ldots, \lambda_{s}\right)$ If the conditions in an inequality $\left(\lambda_{1}, \lambda_{2}, \ldots, \lambda_{s}\right)$ are satisfied then we say that $\left(\lambda_{1}, \lambda_{2}, \ldots, \lambda_{s}\right)$ holds. Sometimes, instead of Lemma 2 , we are able to use induction. The use of this is indicated by putting $\left(^{*}\right)$ on the corresponding part of the partition. For example, if for $\mathrm{n}=10, \mathrm{~B} 5$ is larger than each of $\mathrm{B} 6 ; \mathrm{B} 7 ; \ldots, \ldots ; \mathrm{B} 10$, and if $\frac{B_{1}^{3}}{B_{1} B_{3} B_{4}}>2$ the inequality $\left(4 ; 6^{*}\right)$ gives

$$
4 B_{1}-\frac{1}{2} \frac{B_{1}^{3}}{B_{1} B_{3} B_{4}}+6\left(\mathrm{~B}_{1} \mathrm{~B}_{2} \mathrm{~B}_{3} \mathrm{~B}_{4}\right)^{-1 / 6}>w_{10}
$$

In particular the inequality $\left((\mathrm{n}-1)^{*} ; 1\right)$ always holds. This can be written as

$$
w_{n-1}\left(\mathrm{~B}_{\mathrm{n}}\right) \frac{-1}{(\mathrm{n}-1)}+B_{n}>W_{n}
$$

Also we have $B_{1} \geq 1$ because if $\mathrm{B}_{1}<1$, then $B_{i} \leq B_{1}<1$ for each I contradicting $\mathrm{B} 1 \mathrm{~B} 2::: \mathrm{Bn}=1$.

Using the upper bounds on and the inequality (2.5), we obtain numerical lower and upper bounds on Bn, which we denote by $\ln$ and $\mathrm{mn}$ respectively. We use the approach of Hans-Gill et al. [14], but our method of dealing with

Is somewhat different. In Sections 3-5 we give proof of Theorem 1 for $\mathrm{n}=10 ; 11$ and 12 respectively. The proof of these cases is based on the truncation of the interval $[\mathrm{ln} ; \mathrm{mn}]$ from both the sides.

In this paper we need to maximize or minimize frequently functions of several variables. When we say that a given function of several variables in $\mathrm{x} ; \mathrm{y}$; is an increasing/decreasing function of $\mathrm{x} ; \mathrm{y} ; \ldots .$. it means that the concerned property holds when function is considered as a function of one variable at a time, all other variables being fixed.

\section{Proof of Theorem 1 for $n=10$}

Here we have $\mathrm{W}_{10}=10: 3, \mathrm{~B}_{1}<\gamma_{10}<2: 2636302$. Using (2.5), we have $110=0: 4007<\mathrm{B} 10<1: 9770808=\mathrm{m}_{10}$.

The inequality $\left(9^{*} ; 1\right)$ gives $9(\mathrm{~B} 10)^{\frac{-1}{9}}+\mathrm{B} 10<10: 3$. But for $0: 4398$ $\mathrm{B} 10$ 1:9378, this inequality is not true. Hence we must have either $\mathrm{B} 10<0: 4398$ or $\mathrm{B} 10>1: 9378$. We will deal with the two cases $0: 4007<$ B10<0:4398 and 1:9378<B10<1:9770808 separately:

\section{$0: 4007<\mathrm{B}_{10}<0: 4398$}

Using the Lemmas 3 \& 4 we have:

$$
\left\{\begin{array}{lll}
B_{9} \leq \frac{4}{3} B_{10}<0.5864 & B_{8} \leq \frac{3}{2} B_{10}<0.6597 & B_{7} \leq 2 B_{10}<0.8796 \\
B_{6} \leq \frac{B_{10}}{\varepsilon}<0.9383 & B_{5} \leq \frac{4}{3} \frac{B_{10}}{\varepsilon}<1.2511 & B_{4} \leq \frac{3}{2} \frac{B_{10}}{\varepsilon}<1.4075 \\
B_{3} \leq \frac{2 B_{10}}{\varepsilon}<1.8766 & B_{2} \leq \frac{B_{10}}{(\varepsilon)^{2}}<2.0018 &
\end{array}\right.
$$

Claim(i) $\mathrm{B}_{2}>1: 7046$
The inequality $(2 ; 2 ; 2 ; 2 ; 2)$ w gives $2 \mathrm{~B}_{2}+2 \mathrm{~B}_{4}+2 \mathrm{~B}_{6}+2 \mathrm{~B}_{8}+2 \mathrm{~B}_{10}>10: 3$. Using (3.1), we find that this inequality is not true for $\mathrm{B}_{2} \leq 1: 7046$. Hence we must have $B_{2}>1: 7046$.

Claim(ii) $\mathrm{B}_{2}<1: 8815$

Suppose $B_{2} \geq 1.8815$ then using (3.1) and that $B_{6} \geq \varepsilon B_{2}$ we find that $\frac{B_{2}^{3}}{B_{3} B_{4} B_{5}}>2$ and $\frac{B_{6}^{3}}{B_{7} B_{8} B_{9}}>2$ So the inequality $(1,4,4,1)$ holds, i.e. $B_{1}+4 B_{2}-$

$\frac{1}{2} \frac{B_{2}^{4}}{B_{3} B_{4} B_{5}}+4 B_{6}-\frac{1}{2} \frac{B_{2}^{4}}{B_{7} B_{8} B_{9}}+B_{10}>10.3$ Applying AM-GM inequality we get $B_{1}+4 B_{2}+4 B_{6}+B_{10}-\sqrt{B_{2}^{5} B_{6}^{5} B_{1} B_{10}}>10.3 \quad$ Now since $\varepsilon^{2} B_{2} \leq B_{10}<0.4398 \quad B_{6} \geq \varepsilon B_{2}, B_{1} \geq B_{2}$ and $B_{2} \geq 1.8815$ we find that the left side is a decreasing function of $\mathrm{B}_{10}$ and $\mathrm{B}_{6}$. So replacing $\mathrm{B}_{10}$ by $\varepsilon^{2} B_{2}$ and by $\varepsilon B_{2}$ we get $\varnothing_{1}=B_{1}+\left(4+4 \varepsilon+\varepsilon^{2}\right) \mathrm{B}_{2}-\sqrt{(\varepsilon)^{7} B_{2}^{11} B_{1}}>10.3$ Now the left side is a decreasing function of B2, so replacing B2 by 1.8815 we find that $\varnothing_{1}<10.3$ for $1<\mathrm{B}_{1}<2: 2636302$, a contradiction. Hence we must have $\mathrm{B}_{2}<1: 8815$.

Claim (iii) $\mathrm{B}_{3}<1: 5652$

Suppose $B_{3} \geq 1.5652$ From (3.1) we have $\mathrm{B}_{4} \mathrm{~B}_{5} \mathrm{~B}_{6}<1: 6524$ and $\mathrm{B}_{8} \mathrm{~B}_{9} \mathrm{~B}_{10}$ $<0: 1702$, so we find that $\frac{B_{3}^{3}}{B_{4} B_{5} B_{6}}>2$ and $\frac{B_{7}^{3}}{B_{8} B_{9} B_{10}} \geq \frac{\left(\varepsilon B_{3}\right)^{3}}{B_{8} B_{9} B_{10}}>2$ for $\mathrm{B}_{3}>1: 49$.

Applying AM-GM to inequality $(2,4,4)$ we get $4 B_{1}-\frac{2 B_{1}^{2}}{B_{2}}+4 B_{3}+4 B_{7}-\sqrt{B_{3}^{5} B_{7}^{5} B_{1} B_{2}}>10.3 \quad$ Since $\quad B_{1} \geq B_{2}>1.7046, B_{7} \geq \varepsilon B_{3}$ and $B_{3} \geq 1.5652$ we find that left side is a decreasing function of $\mathrm{B}_{1}$ and $\mathrm{B}_{7}$. So we replace $\mathrm{B}_{1}$ by $\mathrm{B}_{2}, \mathrm{~B}_{7}$ by $\varepsilon B_{3}$ and get that $\varnothing_{2}=2 B_{2}+4(1+\varepsilon) B_{3}-\sqrt{(\varepsilon)^{5} B_{3}^{10} B_{2}^{2}}>10.3$.

But left side is a decreasing function of $\mathrm{B} 3$, so replacing $\mathrm{B} 3$ by 1.5652 we find that $\varnothing_{2}<10.3$ for $1: 7046<\mathrm{B}_{2}<1: 8815$, a contradiction. Hence we must have $\mathrm{B}_{3}<1: 5652$.

Claim (iv) B1 >1:9378

Suppose $B_{1} \leq 1.9378$ Using (3.1) and that $\mathrm{B} 3<1: 5652$, B2 $>1: 7046$, we find that $\mathrm{B}_{2}$ is larger than each of $\mathrm{B}_{3} ; \mathrm{B} 4 ; \ldots ; \mathrm{B} 10$. So the inequality $\left(1 ; 9,{ }^{*}\right)$ holds. This gives $B_{1}+9\left(B_{1}\right)^{-1 / 9}>10.3$ which is not true for $B_{1} \leq 1.9378$ So we must have $\mathrm{B}_{1}>1: 9378$.

\section{Claim (v) B3<1:5485}

Suppose $B_{3} \geq 1.5485$ We proceed as in Claim(iii) and replace $B_{1}$ by 1.9378 and $\mathrm{B}_{7}$ by $\varepsilon B_{3}$ to get that

$$
\varnothing_{3}=4(1.9378)-\frac{2(1.9378)^{2}}{B_{2}}+4(1+\varepsilon) \mathrm{B}_{3}-\sqrt{(\varepsilon)^{5}(1.9378) \mathrm{B}_{3}^{10} B_{2}}>10.3
$$

One easily checks that $\varnothing_{3}<10.3$ for $1.5485 \leq \mathrm{B}_{3}<1: 5652$ and $1: 7046<$ $\mathrm{B}_{2}<1: 8815$. Hence we have $\mathrm{B}_{3}<1: 5485$.

Claim (vi) $\mathrm{B}_{1}<2: 0187$

Suppose $B_{1} \geq 2.0187$ Using (3.1) and Claims (ii), (v) we have $\mathrm{B}_{2} \mathrm{~B}_{3} \mathrm{~B}_{4}<4: 11$. Therefore $\frac{B_{1}^{3}}{B_{2} B_{3} B_{4}}>2$ As $B_{5} \geq \varepsilon B_{1}>0.9462$ we see 
using (3.1) that $\mathrm{B}_{5}$ is larger than each of $\mathrm{B}_{6} ; \mathrm{B}_{7}, \ldots ; \mathrm{B}_{10}$. Hence the inequality $\left(4 ; 6,^{*}\right)$ holds. This gives $\varnothing_{4}=4 B_{1}-\frac{1}{2} \frac{B_{1}^{4}}{B_{2} B_{3} B_{4}}+6\left(\mathrm{~B}_{1} \mathrm{~B}_{2} \mathrm{~B}_{3} \mathrm{~B}_{4}\right)^{-1 / 6}>10.3$ Left side is an increasing function of $\mathrm{B}_{2} \mathrm{~B}_{3} \mathrm{~B}_{4}$ and decreasing function of

B1. So we can replace $\mathrm{B}_{2} \mathrm{~B}_{3} \mathrm{~B}_{4}$ by $4: 11$ and $\mathrm{B} 1$ by 2.0187 to find $\varnothing_{4}<10.3$ a contradiction. Hence we have $\mathrm{B}_{1}<2: 0187$.

\section{Claim (vii) $\mathrm{B}_{4}<1: 337$} Suppose $B_{4} \geq 1.337$ then using $(3.1)$ we get $\frac{B_{4}^{3}}{B_{5} B_{6} B_{7}}>2$ Applying
AMGM to inequality $(1,2,4,2,1)$ we have

$$
B_{1}+4 B_{2}-\frac{2 B_{2}^{2}}{B_{3}}+4 B_{4}+4 B_{8}+B_{10}-2 \sqrt{B_{4}^{5} B_{8}^{5} B_{1} B_{2} B_{3} B_{10}}>10.3
$$

Since $\mathrm{B}_{2}>1: 7046 \quad B_{3} \geq \frac{3}{4} B_{2}, B_{4} \geq 1.337 B_{8} \geq \varepsilon B_{4}$ and $B_{10} \geq \frac{2 \varepsilon}{3} B_{4}$ we find that left side is a decreasing function of $\mathrm{B}_{2}, \mathrm{~B}_{8}$ and $\mathrm{B}_{10}$. So we can replace $\mathrm{B}_{2}$ by $1.7046 ; \mathrm{B}_{8}$ by $\varepsilon B_{4}$ and $B_{10}$ by $\frac{2 \varepsilon}{3} B_{4}$ to get

$$
\varnothing_{5}=B_{1}+4(1.7046)-\frac{2(1.7046)^{2}}{B_{3}}+\left(4+4 \varepsilon+\frac{2 \varepsilon}{3}\right) \mathrm{B}_{4}-2 \sqrt{\frac{2}{3}(\varepsilon)^{4}(1.7046) \mathrm{B}_{4}^{9} B_{1} B_{3}}>10.3
$$

Now left side is a decreasing function of B4, replacing B4 by 1:337, we find that $\varnothing_{5}<10.3$ for $1<\mathrm{B}_{1}<2: 0187$ and $1<\mathrm{B}_{3}<1: 5485$, a contradiction. Hence we have $\mathrm{B}_{4}<1: 337$.

Claim (viii) $\mathrm{B}_{5}<1: 1492$

Suppose $B_{5} \geq 1.1492$ Using (3.1), we get $\mathrm{B}_{6} \mathrm{~B}_{7} \mathrm{~B}_{8}<0: 5445$ : Therefore $\frac{B_{2}^{3}}{B_{6} B_{7} B_{8}}>2$ Also using Lemma $3 \& 4,2 \quad B_{9} \geq 2\left(\varepsilon \mathrm{B}_{5}\right)$ $>1: 077>\mathrm{B}_{10}$. So the inequality $\left(4^{*} ; 4 ; 2\right)$ holds, i.e. 4 $\left(\frac{1}{B_{5} B_{6} B_{7} B_{8} B_{9} B_{10}}\right)^{1 / 4}+4 B_{5}-\frac{1}{2} \frac{B_{5}^{4}}{B_{6} B_{7} B_{8}}+4 B_{9}-\frac{2 B_{9}^{2}}{B_{10}}>10.3$ Now left side is a decreasing function of $\mathrm{B}_{5}$ and $\mathrm{B}_{9}$. So we replace $\mathrm{B}_{5}$ by 1.1492 and $\mathrm{B}_{9}$ by $1.1492 \varepsilon$ and get that $\varnothing_{6}\left(x, B_{10}\right)=4\left(\frac{1}{(\varepsilon)(1.1492)^{2} X b_{10}}\right)^{1 / 4}+4(1+\varepsilon)$ $(1.1492)-\frac{1}{2} \frac{(1.1492)^{4}}{x}-\frac{2(1.1492 \varepsilon)^{2}}{B_{10}}>10.3$ where $\mathrm{x}=\mathrm{B}_{6} \mathrm{~B}_{7} \mathrm{~B}_{8}$. Using Lemma $3 \& 4$ we have $\mathrm{x}=\mathrm{B}_{6} \mathrm{~B}_{7} \mathrm{~B}_{8} \geq \frac{B_{5}^{3}}{4} \geq \frac{(1.1492)^{3}}{4}$ and $B_{10} \geq \frac{3 \varepsilon}{4} B_{5} \geq \frac{3 \varepsilon}{4}(1.1492)$ It can be verified that $\varnothing_{6}\left(x, \mathrm{~B}_{10}\right)<10.3$ for $\frac{(1.1492)^{3}}{4} \leq x<0.5445$ and $\frac{3 \varepsilon}{4}(1.1492) \leq \mathrm{B}_{10}<0.4398$ giving thereby a contradiction. Hence we must have $\mathrm{B}_{5}<1: 1492$.

Claim (ix) $\mathrm{B}_{2}<1: 766$.

Suppose $B_{2} \geq 1.766$ We have $\mathrm{B}_{3} \mathrm{~B}_{4} \mathrm{~B}_{5}<2: 3793$. So $\frac{B_{2}^{3}}{B_{3} B_{4} B_{5}}>2$ Also $B_{6} \geq \varepsilon B_{2}>0.8277$ Therefore $\mathrm{B} 6$ is larger than ${ }_{3} B_{4} B_{5}$ each $B_{7}, B_{8}, B_{9} B_{10}$ Hence the inequality $\left(1 ; 4 ; 5,{ }^{*}\right)$ holds. This gives $B_{1}+4 B_{2}-\frac{1}{2} \frac{B_{2}^{4}}{B_{3} B_{4} B_{5}}+5\left(\frac{1}{B_{1} B_{2} B_{3} B_{4} B_{5}}\right)^{\frac{1}{5}}>10.3 \quad$ Left side is an increasing function of $\mathrm{B}_{3} \mathrm{~B}_{4} \mathrm{~B}_{5}$, a decreasing function of $\mathrm{B}_{2}$ and an increasing function of $B_{1}$. One easily checks that this inequality is not true for $\mathrm{B}_{1}<2: 0187$

$B_{2} \geq 1.766$ and $\mathrm{B}_{3} \mathrm{~B}_{4} \mathrm{~B}_{5}<2: 3793$ : Hence we have $\mathrm{B}_{2}<1: 766$.

Final contradiction

As $2\left(\mathrm{~B}_{2}+\mathrm{B}_{4}+\mathrm{B}_{6}+\mathrm{B}_{8}+\mathrm{B}_{10}\right)<2(1: 766+1: 337+0: 9383+0: 6597+0: 4398)<10: 3$, the weak inequality $(2 ; 2 ; 2 ; 2 ; 2) \mathrm{w}$ gives a contradiction.

\section{$\mathbf{9 3 7 8}<\mathrm{B}_{10}<\mathbf{1 : 9 7 7 0 8 0 8}$}

Here $B_{1} \geq B_{10}>1.9378$ and $\mathrm{B}_{2}=\left(\mathrm{B}_{1} \mathrm{~B}_{3} \ldots \mathrm{B}_{10}\right)^{-1}$

$\leq\left(\mathrm{B}_{1} \mathrm{~B}_{2} \mathrm{~B}_{4} \ldots \mathrm{B}_{10}\right)^{-1} \leq\left(\frac{3}{32} \varepsilon^{3} \mathrm{~B}_{3}^{6} \mathrm{~B}_{1}^{2} \mathrm{~B}_{10}\right)^{-1}=\left(\frac{1}{16} \varepsilon^{4} \mathrm{~B}_{2}^{7} \mathrm{~B}_{1} \mathrm{~B}_{10}\right)^{-1}$

Which implies $\left(\mathrm{B}_{2}\right)^{8} \leq\left(\frac{1}{16} \varepsilon^{4}(1.9378)^{2}\right)^{-1}$ i.e. $\mathrm{B} 2<1: 75076$.

Similarly

$$
\begin{aligned}
& B_{3}=\left(\mathrm{B}_{1} \mathrm{~B}_{2} \mathrm{~B}_{4} \ldots \mathrm{B}_{10}\right)^{-1} \leq\left(\frac{3}{32} \varepsilon^{3} \mathrm{~B}_{3}^{6} \mathrm{~B}_{1}^{2} \mathrm{~B}_{10}\right)^{-1} \\
& B_{4}=\left(\mathrm{B}_{1} \mathrm{~B}_{2} \mathrm{~B}_{3} \mathrm{~B}_{5} \ldots \mathrm{B}_{10}\right)^{-1} \leq\left(\frac{3}{32} \varepsilon^{2} \mathrm{~B}_{4}^{5} \mathrm{~B}_{1}^{3} \mathrm{~B}_{10}\right)^{-1} \\
& B_{6}=\left(\mathrm{B}_{1} \ldots \mathrm{B}_{5} \mathrm{~B}_{7} \mathrm{~B}_{8} \mathrm{~B}_{9} \mathrm{~B}_{10}\right)^{-1} \leq\left(\frac{1}{16} \varepsilon \mathrm{B}_{6}^{3} \mathrm{~B}_{1}^{3} \mathrm{~B}_{10}\right)^{-1} \\
& B_{8}=\left(\mathrm{B}_{1} \ldots \mathrm{B}_{7} \mathrm{~B}_{9} \mathrm{~B}_{10}\right)^{-1} \leq\left(\frac{3}{32} \varepsilon^{3} \mathrm{~B}_{8} \mathrm{~B}_{1}^{7} \mathrm{~B}_{10}\right)^{-1}
\end{aligned}
$$

These respectively give $\mathrm{B}_{3}<1: 46138, \mathrm{~B}_{4}<1: 22883, \mathrm{~B}_{6}<0: 896058$ and $\mathrm{B}_{8}<0: 721763$. So we have $B_{1}^{4} B_{5} B_{6} B_{7} B_{8} B_{9} B_{10}=\frac{B_{1}^{3}}{B_{2} B_{3} B_{4}}>2$ Also $2 B_{5} \geq 2\left(\varepsilon \mathrm{B}_{1}\right)>1.8166>\mathrm{B}_{6}$ and $2 B_{7} \geq 2\left(\frac{2 \varepsilon}{3} \mathrm{~B}_{1}\right)>\mathrm{B}_{8}$ Applying AMGM to inequality $(4,2,2,1,1)$ we have $4 B_{1}+4 B_{5}+4 B_{7}+B_{9}+B_{10}$ -3 $\quad\left(2 \mathrm{~B}_{1}^{5} \mathrm{~B}_{5}^{3} \mathrm{~B}_{7}^{3} \mathrm{~B}_{9} \mathrm{~B}_{10}\right)^{\frac{1}{3}}>10.3$ We find that left side is a decreasing function of $\mathrm{B}_{7}$ and $\mathrm{B}_{5}$, so can replace $\mathrm{B}_{7}$ by $\frac{2}{3} \varepsilon B_{1}$ and $\mathrm{B}_{5}$ by $\varepsilon B_{1}$ then it is a decreasing function of $B_{1}$, so replacing $B_{1}$ by $B_{10}$ we have $4\left(1+\varepsilon+\frac{2}{3} \varepsilon\right) \mathrm{B}_{10}+\mathrm{B}_{9}+\mathrm{B}_{10}-2^{\frac{4}{3}}(\varepsilon)^{2}\left(\mathrm{~B}_{10}\right) 4\left(\mathrm{~B}_{9}\right)^{\frac{1}{3}}>10.3$ which is not true for $(1.9378) \varepsilon^{2}<B_{9} \leq B_{1}<2.2636302$ and $1: 9378<\mathrm{B} 10<1: 9770808$. Hence we get a contradiction.

\section{Proof of Theorem 1 for $n=11$}

Here we have $\mathrm{w}_{11}=11.62, B_{1} \leq \gamma_{11}<2.393347$ Using (2.5), we have $\mathrm{l}_{11}=0: 3673<\mathrm{B}_{11}<2: 1016019=\mathrm{m}_{11}$.

The inequality $\left(10^{*} ; 1\right)$ gives $10: 3\left(\mathrm{~B}_{11}\right)^{\frac{-1}{10}}+B_{11}>11.62$ But for $0.4409 \leq B_{11} \leq 2.018$ this inequality is not true. So we must have either $B_{11}<0.4409$ or $\mathrm{B}_{11}>2: 018$.

\section{$0: 3673<\mathrm{B} 11<0: 4409$}

Claim (i) B10<0:4692

Suppose $B_{10} \geq 0.4692$ then $2 \mathrm{~B}_{10}>\mathrm{B}_{11}$, so $\left(9^{*} ; 2\right)$ holds, i.e. 9 $\left(\frac{1}{B_{10} B_{11}}\right)^{\frac{1}{9}}+4 B_{10}-\frac{2 B_{10}^{2}}{B_{11}}>11.62$ As left side is a decreasing function of $B_{10}$, we can replace $B_{10}$ by 0.4692 and find that it is not true for $0: 3673<\mathrm{B}_{11}<0: 4409$.

Hence we must have $\mathrm{B}_{10<} 0: 4692$.

Using Lemmas 3 and 4 we have:

$$
\begin{aligned}
& B_{9} \leq \frac{4}{3} B_{10}<0.6256, B_{8} \leq \frac{3}{2} B_{10}<0.7038, B_{7} \leq \frac{B_{11}}{\varepsilon}<0.94063 \\
& B_{6} \leq \frac{B_{10}}{\varepsilon}<1.00 . ., B_{5} \leq \frac{4}{3} \frac{B_{10}}{\varepsilon}<1.3347, B_{4} \leq \frac{3}{2} \frac{B_{10}}{\varepsilon}<1.50151
\end{aligned}
$$


$B_{3} \leq \frac{B_{11}}{\varepsilon^{2}}<2.0068, B_{2} \leq \frac{B_{10}}{\varepsilon^{2}}<2.13557$

\section{Claim (ii) B2 >1:913}

The inequality $(2 ; 2 ; 2 ; 2 ; 2 ; 1)$ w gives $2 \mathrm{~B}_{2}+2 \mathrm{~B}_{4}+2 \mathrm{~B}_{6}+2 \mathrm{~B}_{8}+2 \mathrm{~B}_{10}+\mathrm{B}_{11}>$

11:62. Using (4.1) we find that this inequality is not true for $B_{2} \leq 1.913$ so we must have $\mathrm{B}_{2}>1: 913$.

\section{Claim(iii) B3<1:761}

Suppose $B_{3} \geq 1.761$ then wehave $\frac{B_{3}^{3}}{B_{4} B_{5} B_{6}}>2$ and $\frac{B_{7}^{3}}{B_{8} B_{9} B_{10}}>\frac{\left(\varepsilon \mathrm{B}_{3}\right)^{3}}{B_{8} B_{9} B_{10}}>$

2. Applying AM-GM to the inequality $(2,4,4,1)$ we get $4 B_{1}-\frac{2 B_{1}^{2}}{B_{2}}+4 B_{3}+4 B_{7}+B_{11}-\sqrt{B_{3}^{5} B_{7}^{5} B_{1} B_{2} B_{11}}>11.62$ One easily finds that it is not true for $B_{1} \geq B_{2}>1.913, B_{3} \geq 1.761, B_{7} \geq \varepsilon B_{3}, B_{11} \geq \varepsilon^{2} B_{3}, 1.913<B_{2}<2.13557$ and $1.761 \leq B_{3}<2.0068$ Hence we must have $\mathrm{B}_{3}<1: 761$ :

\section{Claim (iv) B1<2:2436}

Suppose $B_{1} \geq 2.2436$ As $\mathrm{B}_{2} \mathrm{~B}_{3} \mathrm{~B}_{4<} 2: 13557 \times 1: 761 \times 1: 50151<5: 6468$, we have $\frac{B_{1}^{3}}{B_{2} B_{3} B_{4}}>2$ Also $B_{5} \geq \varepsilon B_{1}>1.051$ so $\mathrm{B} 5$ is larger than each of $\mathrm{B} 6 ; \mathrm{B} 7 \ldots ; \mathrm{B} 11$. Hence the inequality $\left(4 ; 7,{ }^{*}\right)$ holds. This gives $4 B_{1}-\frac{1}{2} \frac{B_{1}^{4}}{B_{2} B_{3} B_{4}}+7\left(\frac{1}{B_{1} B_{2} B_{3}}\right)^{\frac{1}{7}}>11.62$ Left side is an increasing function of $\mathrm{B}_{2} \mathrm{~B}_{3} \mathrm{~B}_{4}$ and decreasing function of $\mathrm{B}_{1}$. One easily checks that the inequality is not true for $\mathrm{B}_{2} \mathrm{~B}_{3} \mathrm{~B}_{4}<5: 6468$ and $\mathrm{B} 1 \geq 2: 2436$. Hence we have $\mathrm{B}_{1}<2: 2436$.

\section{Claim (v) B4<1.4465 and B2>1:9686}

Suppose $\mathrm{B}_{4} \geq 1.4465$ We have B5B6B7 $<1: 2569$ and $\mathrm{B}_{9} \mathrm{~B}_{10} \mathrm{~B}_{11}<0: 1295$. Therefore for $\mathrm{B}_{4}>1: 36$, we have $\frac{B_{4}^{3}}{B_{5} B_{6} B_{7}}>2$ and $\frac{B_{8}^{3}}{B_{9} B_{10} B_{11}}>\frac{\left(\varepsilon \mathrm{B}_{4}\right)^{3}}{B_{9} B_{10} B_{11}}>2$ So the inequality $(1,2,4,4)$ holds. Applying AM-GM to inequality $(1,2,4,4)$, we get $B_{1}+4 B_{2}-\frac{2 B_{2}^{2}}{B_{3}}+4 B_{8}-\sqrt{B_{4}^{5} B_{8}^{5} B_{1} B_{2} B_{3}}>11.62$ A simple calculation shows that this is not true for $B_{1} \geq B_{2}>1.913$, $B_{4} \geq 1.4465, B_{8} \geq \varepsilon B_{4} \geq 1.4465, B_{1}<2.2436$ and $B_{3}<1.761$ Hence we have $\mathrm{B} 4<1: 4465$.

Further if $B_{2} \leq 1.9686$ then $2 \mathrm{~B}_{2}+2 \mathrm{~B}_{4}+2 \mathrm{~B}_{6}+2 \mathrm{~B}_{8}+2 \mathrm{~B}_{10}+\mathrm{B}_{11}<11: 62$. So the inequality $(2 ; 2 ; 2 ; 2 ; 2 ; 1)$ gives a contradiction.

\section{Claim (vi) B4<1:4265 and B2 $>1: 9888$}

Suppose $B_{4} \geq 1.4265$ We proceed as in Claim (v) and get a contradiction with improved bounds on $\mathrm{B}_{2}$ and $\mathrm{B}_{4}$.

\section{Claim (vii) B1<2:2056}

Suppose $B_{1} \geq 2.2056$ As B3B4B5<1:761 × 1:4265 × 1:3347<3:3529, we have $\frac{B_{2}^{3}}{B_{3} B_{4} B_{5}}>2$ Also $B_{6} \geq \varepsilon B_{2}>0.9491$ so $\mathrm{B} 6$ is larger than each of $\mathrm{B} 7 ; \mathrm{B} 8, \ldots, \mathrm{B} 11$. Hence the inequality $\left(1 ; 4 ; 6^{*}\right)$ holds, i.e. $\mathrm{B} 1+4 \mathrm{~B} 2-$ $\frac{1}{2} \frac{B_{2}^{4}}{B_{3} B_{4} B_{5}}+6\left(\frac{1}{B_{1} B_{2} B_{3} B_{4} B_{5}}\right)^{\frac{1}{6}}>11.62$

\section{Claim (ix) B1<2:1669}

Suppose $B_{1} \geq 2.1669$ We proceed as in Claim(iv) and get a contradiction with improved bounds on $\mathrm{B}_{1}, \mathrm{~B}_{2}$ and $\mathrm{B}_{4}$

\section{Claim (x) B4<1:403 and B2 $>2: 012$}

Suppose $B_{4} \geq 1.403 \mathrm{We}$ proceed as in Claim(v) and get a contradiction with improved bounds on B2 and B4.

\section{Final Contradiction:}

As now B3B4B5 $<1: 761 \times 1: 403$ 1:3347<3:2977, we have $\frac{B_{2}^{3}}{B_{3} B_{4} B_{5}}>2$ for B2>2:012. Also $B_{6} \geq \varepsilon B_{2}>0.943>$ each of B7; B8; B11. Hence the inequality $(1 ; 4 ; 6)$ holds. Proceeding as in Claim (viii) we find that this inequality is not true for $\mathrm{B}_{1}<2: 1669 ; \mathrm{B}_{2}>2: 012$ and $\mathrm{B}_{3} \mathrm{~B}_{4} \mathrm{~B}_{5}<3: 2977$; giving thereby a contradiction.

\section{2:018<B11<2:1016019}

Here $B_{1} \geq B_{11}>2.018$ Therefore using Lemmas $3 \& 4$ we have $\mathrm{B} 10=(\mathrm{B} 1 \mathrm{~B} 9 \mathrm{~B} 11)^{-1}$

$$
\begin{aligned}
& \leq\left(\mathrm{B}_{1} \cdot \frac{3}{4} \mathrm{~B}_{1} \cdot \frac{2}{3} \mathrm{~B}_{1} \frac{1}{2} \mathrm{~B}_{1} \varepsilon \mathrm{B}_{1} \frac{3}{4} \varepsilon \mathrm{B}_{1} \frac{2}{3} \varepsilon \mathrm{B}_{1} \frac{1}{2} \varepsilon \mathrm{B}_{1} \varepsilon^{2} \mathrm{~B}_{1} \cdot \mathrm{B}_{1}\right)^{-1} \\
& =\left(\frac{1}{16} \varepsilon^{6} \mathrm{~B}_{1}^{9} \mathrm{~B}_{11}\right)^{-1}<\left(\frac{1}{16} \varepsilon^{6}(2.018)^{10}\right)^{-1}<1.34702
\end{aligned}
$$

Similarly $B_{4}=\left(\mathrm{B}_{1} \mathrm{~B}_{2} \mathrm{~B}_{3} \mathrm{~B}_{4} \cdots \mathrm{B}_{11}\right)^{-1} \leq\left(\frac{1}{16} \varepsilon^{3} \mathrm{~B}_{1}^{3} \mathrm{~B}_{11}\right)^{-1}$ which gives $\mathrm{B} 4<1: 37661$.

\section{Claim (i) B10<0:4402}

The inequality $\left(9^{*} ; 1 ; 1\right)$ gives $9\left(\frac{1}{B_{10} B_{11}}\right)^{\frac{1}{9}}+B_{10}+B_{11}>11.62$ But this inequality is not true for $0.4402 \leq B_{10}<1: 34702$ and 2:018<B11<2:1016019. Hence we must have $\mathrm{B} 10<0: 4402$.

Now we have $B_{9} \leq \frac{4}{3} B_{10}<0: 58694, B_{8} \leq \frac{3}{2} B_{10}<0.6603, B_{7} \leq 2 B_{10}<0.8804$ and $B_{6} \leq \frac{B_{10}}{\varepsilon}<0.93914$

\section{Claim (ii) B7<0:768}

Suppose $B_{7} \geq 0.768$ Then $\frac{B_{7}^{3}}{B_{8} B_{9} B_{10}}>2$ so $\left(6^{*} ; 4 ; 1\right)$ holds. This gives $\varnothing_{7}(\mathrm{x})=6(\mathrm{x})^{1 / 6}+4 B_{7}-\frac{1}{2} B_{7}^{5} B_{11} x+B_{11}>11.62$ where $\mathrm{x}=\mathrm{B}_{1} \mathrm{~B}_{2}:$ : $: \mathrm{B}_{6}$. The function $\varnothing_{7}(\mathrm{x})$ has its maximum value at $x=\left(\frac{2}{B_{7}^{5} B_{11}}\right)^{6 / 5}$ Therefore $\varnothing_{7}(\mathrm{x}) \leq \varnothing_{7}\left(\left(\frac{2}{B_{7}^{5} B_{11}}\right)^{6 / 5}\right)$ which is less than 11:62 for $0.768 \leq B_{7}<0.88042: 018<\mathrm{B} 11<2: 1016019$. This gives a contradiction.

Now $B_{5} \leq \frac{3}{2} B_{7}<1.1521$ and $B_{3} \leq \frac{B_{7}}{\varepsilon}<1.6385$

\section{Claim (iii) B2<1:795}

Suppose $B_{2} \geq 1.795$ then $\frac{B_{2}^{3}}{B_{3} B_{4} B_{5}}>2$ and $\frac{B_{6}^{3}}{B_{7} B_{8} B_{9}}>2$ Applying AMGM to the inequality $(1,4,4,1,1)$ p we get $\mathrm{B} 1+4 \mathrm{~B} 2+4 \mathrm{~B} 6+\mathrm{B} 10$ $+\mathrm{B} 11-\sqrt{B_{2}^{5} B_{6}^{5} B_{1} B_{10} B_{11}}>11.62 \mathrm{We}$ find that left side is a decreasing function of $\mathrm{B}_{6}$, so we first replace $\mathrm{B}_{6}$ by $\varepsilon B_{2}$ then it is a decreasing function of $B_{2}$, so we replace $B_{2}$ by 1.795 and get that

$$
\varnothing_{8}\left(\mathrm{~B}_{11}\right)=\mathrm{B}_{1}+4(1+\varepsilon)(1.795)+\mathrm{B}_{10}+B_{11}-\sqrt{(\varepsilon)^{5}(1.795)^{10} B_{1} B_{10} B_{11}}>11.62
$$


Citation: Kathuria L, Raka M (2015) Refined Estimates on Conjectures of Woods and Minkowski-I. J Appl Computat Math 4: 209. doi:10.4172/21689679.1000209

Page 7 of 10

Now $\varnothing_{8}\left(\mathrm{~B}_{11}\right)>0$ so $\varnothing_{8}\left(\mathrm{~B}_{11}\right)<\max \left\{\varnothing_{8}(2.018), \varnothing_{8}(2.1016019)\right\}$ which can be verified to be at most 11.62 for $(\varepsilon)^{2}(1.795) \leq \mathrm{B}_{10}<0.4402$ and $2: 018<\mathrm{B} 1<2: 393347$, giving thereby a contradiction.

\section{Claim (iv) B5<0:98392}

Suppose $B_{5} \geq 0.98392$ We have $\frac{B_{1}^{3}}{B_{2} B_{3} B_{4}}>2$ and $\frac{B_{5}^{3}}{B_{6} B_{7} B_{8}}>2$ Also $2 B_{9} \geq 2\left(\varepsilon \mathrm{B}_{5}\right)>\mathrm{B}_{10}$ Applying AM-GM to the inequality $(4 ; 4 ; 2 ; 1)$ we get $4 B_{1}+4 B_{5}+4 B_{9}-\frac{2 B_{9}^{2}}{B_{10}}+B_{11}-\sqrt{B_{1}^{5} B_{5}^{5} B_{9} B_{10} B_{11}}>11.62$ One can easily check that left side is a decreasing function of $\mathrm{B}_{9}$ and $\mathrm{B}_{1}$ so we can replace $\mathrm{B}_{9}$ by $\varepsilon B_{5}$ and B1byB11 toget $\varnothing_{9}=5 B_{11}+4(1+\varepsilon) \mathrm{B}_{5}-\frac{2\left(\varepsilon \mathrm{B}_{5}\right)^{2}}{B_{10}}-\sqrt{\varepsilon B_{11}^{6} B_{5}^{6} B_{10}}>11.62$ Now the left side is a decreasing function of B5, so replacing B5 by 0.98392 we see that $\varnothing_{9}<11.62$ for $\frac{3 \varepsilon}{4}(0.98392)<\mathrm{B}_{10}<0.4409$ and $2: 018<\mathrm{B} 11<2: 1016019$, a contradiction.

\section{Final Contradiction:}

As in Claim(iv), we have $\frac{B_{1}^{3}}{B_{2} B_{3} B_{4}}>2$ Also $B_{5} \geq \varepsilon B_{1}>0.9458$ each of $\mathrm{B}_{6} ; \mathrm{B}_{7}, \ldots, \mathrm{B}_{10}$. Therefore the inequality $\left(4 ; 6^{*} ; 1\right)$ holds, i.e. $\varnothing_{10}=4 B_{1} \frac{1}{2} \frac{B_{1}^{4}}{B_{2} B_{3} B_{4}}+6\left(\frac{1}{B_{1} B_{2} B_{3} B_{4} B_{11}}\right)^{\frac{1}{6}}+B_{11}>11.62$ Left side is an increasing function of $\mathrm{B}_{2} \mathrm{~B}_{3} \mathrm{~B}_{4}$ and $\mathrm{B}_{11}$ and decreasing function of $\mathrm{B}_{1}$. Using $\mathrm{B}_{5}<0: 98392$, we have $B_{3} \leq \frac{3}{2} B_{5}<1.47588$ and $B_{4} \leq \frac{4}{3} B_{5}<1.311894$ One easily checks that $\varnothing_{10}<11.62$ for $\mathrm{B}_{2} \mathrm{~B}_{3} \mathrm{~B}_{4}<1: 795 \times 1: 47588 \times 1: 311894$, B11<2:1016019 and $B_{1} \geq 2.018$ Hence we have a contradiction.

\section{Proof of Theorem 1 for $n=12$}

Here we have $\mathrm{w}_{12}=13, B_{1} \leq \gamma_{12}<2.5217871$ Using (2.5), we have 112 $=0: 3376<\mathrm{B}_{12}<2: 2254706=\mathrm{m}_{12}$ and using (2.3) we have $B_{1} B_{2}^{11} \leq \gamma_{11}^{11}$ i.e $B_{2} \leq \gamma_{11}^{\frac{11}{12}}<2.2254706$

The inequality $\left(11^{*} ; 1\right)$ gives $11: 62\left(B_{12}\right)^{-1 / 11}+B 12>13$. But this is not true for $0.4165 \leq B_{12} \leq 2.17$ So we must have either $\mathrm{B} 12<0: 4165$ or B12>2:17.

\section{$0: 3376<\mathrm{B} 12<0: 4165$}

Claim (i) B11<0:459

Suppose $B_{11} \geq 0.459$ then $B_{12} \geq \frac{3}{4} B_{11}>0.34425$ and $2 \mathrm{~B} 11>\mathrm{B}_{12}$, so $\left(10^{*} ; 2\right)$ holds, i.e. $\phi_{11}=10.3\left(\frac{1}{B_{11} B_{12}}\right)^{\frac{1}{10}}+4 B_{11}-\frac{2 B_{11}^{2}}{B_{12}}>13$ Left side is a decheasing function of $\mathrm{B} 11$, so we can replace $\mathrm{B} 11$ by .459 to find that $P_{11}<13$ for 0:34425<B12<0:4165, a contradiction. Hence we have $\mathrm{B}_{11}<0: 459$.

\section{Claim (ii) B10<0:5432}

Suppose $B_{10} \geq 0.5432$ From Lemma 3, $B_{11} B_{12} \geq \frac{1}{2} B_{10}^{2}$ and $B_{10} \leq \frac{3}{2} B_{12}$. Therefore $\frac{1}{2}(0.5432)^{2} \leq B_{11} B_{12}<0.1912$ and $B_{10}^{2}>B_{11} B_{12}$ so the inequality $\left(9^{\star}\right.$; 3) holds, i.e. $9\left(\frac{1}{B_{10} B_{11} B_{12}}\right)^{\frac{1}{9}}+4 B_{10}-\frac{B_{10}^{3}}{B_{11} B_{12}}>13$ One easily checks that it is not true noting that left side is a decreasing function of $B_{10}$. Hence we must have $\mathrm{B}_{10}<0: 5432$.

\section{Claim (iii) B9<0:6655}

Suppose $B_{9} \geq 0.6655$ then $\frac{B_{9}^{3}}{B_{10} B_{11} B_{12}}>2$ So the inequality $\left(8^{*}\right.$; 4) holds. This gives $\phi_{12}(\mathrm{x})^{1 / 8}+4 B_{9}-\frac{1}{2} B_{9}^{5} x>13$ where $\mathrm{x}=\mathrm{B}_{1} \mathrm{~B}_{2} \quad \ldots$ $\mathrm{B}_{8}$. The function $\phi_{12}(\mathrm{x})$ has its maximum value at $x=\left(\frac{2}{B_{9}^{5}}\right)^{\frac{8}{7}}$ so $\phi_{12}(\mathrm{x})<\phi_{12}\left(\left(\frac{2}{B_{9}^{5}}\right)^{\frac{8}{7}}\right)<13$ for $0.6655 \leq B_{9}-\frac{1}{2} B_{9}^{5} x>13$ where $\mathrm{x}=\mathrm{B}_{1} \mathrm{~B}_{2}$. B8. The function $\phi_{12}(\mathrm{x})$ has its maximum value at $x=\left(\frac{2}{B_{9}^{5}}\right)^{\frac{8}{7}}$ so $\phi_{12}(\mathrm{x})<x=\left(\frac{2}{B_{9}^{5}}\right)^{\frac{8}{7}}<13$ for $0: 6655 \leq B_{9} \leq \frac{3}{2} B_{11}<0.6885$ This gives a
contradiction.

Using Lemmas 3 \& 4 we have:

$$
\begin{aligned}
& B_{8} \leq \frac{3}{2} B_{10}<0.8148, B_{7} \leq \frac{B_{11}}{\varepsilon}<0.9793, B_{6} \leq \frac{B_{10}}{\varepsilon}<1.1589 \\
& B_{5} \leq \frac{B_{9}}{\varepsilon}<1.4198, B_{4} \leq \frac{3}{2} \frac{B_{10}}{\varepsilon}<1.7384, B_{3} \leq \frac{B_{11}^{\varepsilon}}{\varepsilon^{2}}<2.0892
\end{aligned}
$$

Claim (iv) B2 >1:828, B4>1:426, B6>1:019 and B8>0:715

Suppose $B_{2} \leq 1.828$ Then $2(\mathrm{~B} 2+\mathrm{B} 4+\mathrm{B} 6+\mathrm{B} 8+\mathrm{B} 10+\mathrm{B} 12)<2(1: 828+$ $1: 7384+1: 1589+0: 8148+0: 5432+0: 4165)<13$, giving thereby a contradiction to the weak inequality $(2 ; 2 ; 2 ; 2 ; 2 ; 2) \mathrm{w}$.

Similarly we obtain lower bounds on $\mathrm{B}_{4} ; \mathrm{B}_{6}$ and $\mathrm{B}_{8}$ using $(2 ; 2 ; 2 ; 2 ; 2 ; 2) \mathrm{w}$.

Claim(v) B2>2:0299

Suppose $B_{2} \leq 2.0299$ Consider following two cases:

Case (i) B3>B4

We have $\mathrm{B} 3>\mathrm{B} 4>1: 426>$ each of $\mathrm{B} 5, \ldots, \mathrm{B} 12$. So the inequality $(2$; $\left.10^{*}\right)$ holds, i.e. $4 B_{1}-\frac{2 B_{1}^{2}}{B_{2}}+10.3\left(\frac{1}{B_{1} B_{2}}\right)^{\frac{1}{10}}>13$ The left side is a decreasing function of $B_{1}$, so replacing $B_{1}$ by $B_{2}$ we get $2 B 2+10: 3\left(\frac{1}{B_{2}^{2}}\right)^{\frac{1}{10}}>13$ which is not true for $B_{2} \leq 2.0299$

Case (ii) $B_{3} \leq B_{4}$

As $\mathrm{B} 4>1: 426>$ each of $\mathrm{B} 5, \ldots, \mathrm{B} 12$, the inequality $\left(3 ; 9^{*}\right)$ holds, i.e. $\quad \phi_{13}(\mathrm{X})=4 \mathrm{~B}_{1}-\frac{B_{1}^{3}}{x}+9\left(\frac{1}{B_{1} x}\right)^{\frac{1}{9}}>13 \quad$ where $\mathrm{X}=\mathrm{B} 2 \mathrm{~B} 3<\min$ $\left\{\mathrm{B}_{1}^{2},(2.0299)(1.7384)\right\}=\alpha$ say. Now $\phi_{13}(\mathrm{X})$ is an increasing function of $\mathrm{X}$ for $B_{1} \geq B_{2}>1.828$ and So $\phi_{13}(\mathrm{x})<\phi_{13}(\mathrm{X})$ which can be seen to be less than 13. Hence we have $\mathrm{B} 2>2: 0299$.

\section{Claim (vi) B1 $>2: 17$ and $\mathrm{B} 3<1: 9517$}

Using (2.3) we have $B_{3} \leq\left(\frac{\gamma_{10}^{10}}{B_{1} B_{2}}\right)^{\frac{1}{10}}<1.9648$ Therefore $B_{2}>2: 0299>$ each of $B_{3}, \ldots, B_{12}$. So the inequality $\left(1 ; 11^{\star}\right)$ holds, i.e. $B_{1}+11: 62\left(\frac{1}{B_{1}}\right)^{\frac{1}{11}}>13$ But this is not true for $B_{1} \leq 2.17$ So we must have B1>2:17: Again using (2.3) we have $B_{3}<\left(\frac{2.2636302}{2.17 \times 2.0299}\right)^{\frac{1}{10}}<1.9517$

\section{Claim (vii) B4<1:646}

Suppose $B_{4} \geq 1.646$ From(5.1) andClaims(i)-(iii), wehave $\frac{B_{4}^{3}}{B_{5} B_{6} B_{7}}>2$ and $\frac{B_{8}^{3}}{B_{9} B_{10} B_{11}}>\frac{\left(\varepsilon \mathrm{B}_{4}\right)^{3}}{B_{9} B_{10} B_{11}}>2$ Applying AM-GM to the inequality $(1,2,4,4,1)$ we get $\quad \phi_{14}=B_{1}+4 B_{2}-\frac{2 B_{2}^{2}}{B_{3}}+4 B_{4}+4 B_{8}+B_{12}-\sqrt{B_{4}^{5} B_{8}^{5} B_{1} B_{2} B_{3} B_{12}}>13$ We find that left side is a decreasing function of B2, B8 and B12. So we 
can replace $\mathrm{B} 2$ by $2: 0299, \mathrm{~B} 8$ by "B 4 and $\mathrm{B} 12$ by $\varepsilon^{2} \mathrm{~B}_{4}$. Then it turns a decreasing function of $\varepsilon^{2} \mathrm{~B}_{4}$, so can replace $\mathrm{B} 4$ by 1.646 to find that $\phi_{14}<13$ for $\mathrm{B}_{1}<2: 52178703$ and $\mathrm{B}_{3}<1: 9517$, a contradiction. Hence we have $\mathrm{B}_{4}<1: 646$.

\section{Claim (viii) $\mathrm{B} 1<2: 4273$}

Suppose B1 $\geq 2: 4273$. Consider following two cases:

Case (i) $\mathrm{B}_{5}>\mathrm{B}_{6}$

Here $\mathrm{B}_{5}>$ each of $\mathrm{B}_{6, \ldots} \mathrm{B}_{12}$ as $\mathrm{B}_{5} \geq \varepsilon \mathrm{B}_{1}>1.137$ >each of $\mathrm{B} 7, \ldots, \mathrm{B} 12$. Also B2B3B4<2:2254706 $\times 1: 9517 \times 1: 646<7: 15$. So $\frac{B_{1}^{3}}{B_{2} B_{3} B_{4}}>2$ Hence the inequality $\left(4 ; 8^{\star}\right)$ holds. This gives $4 B_{1}-\frac{1}{2} \frac{B_{1}^{4}}{B_{2} B_{3} B_{4}}+8\left(\mathrm{~B}_{1} \mathrm{~B}_{2} \mathrm{~B}_{3} \mathrm{~B}_{4}\right)^{-1 / 8}>13$ Left side is an increasing function of $\mathrm{B}_{2} \mathrm{~B}_{3} \mathrm{~B}_{4}$ and decreasing function of $B_{1}$. So we can replace $B_{2} B_{3} B_{4}$ by 7.15 and $B_{1}$ by 2.4273 to get a contradiction

Case (ii) $B_{5} \leq B_{6}$

Using (5.1) we have $B_{5} \leq B_{6}<1: 1589$ and so $B_{4} \leq \frac{4}{3} B_{5}<1.5452$ Therefore $\frac{B_{2}^{3}}{B_{3} B_{4} B_{5}}>2$ as $\mathrm{B} 2>2: 0299$ and $\mathrm{B}_{3}<1: 9517$. Also from Claim (iv), $\mathrm{B}_{6}>1: 019>$ each of $\mathrm{B}_{7}, \ldots, \mathrm{B}_{12}$. Hence the inequality $\left(1 ; 4 ; 7^{\star}\right)$ holds. This gives $B_{1}+4 B_{2}-\frac{1}{2} \frac{B_{2}^{4}}{B_{4} B_{5} B_{6}}+7 \quad 7\left(\mathrm{~B}_{1} \mathrm{~B}_{2} \mathrm{~B}_{3} \mathrm{~B}_{4} \mathrm{~B}_{5}\right)^{-1 / 7}>13$ : Left side is an increasing function of $B_{3} B_{4} B_{5}$ and $B_{1}$ and a decreasing function of $B_{2}$. One can check that inequality is not true for $\mathrm{B}_{3} \mathrm{~B}_{4} \mathrm{~B}_{5}<1: 9517 \times 1: 5452 \times 1: 1589$, $\mathrm{B}_{1}<2: 5217871$ and for $\mathrm{B}_{2}>2: 0299$ : Hence we must have $\mathrm{B}_{1}<2: 4273$ :

\section{Claim (ix) B5<1:396}

Suppose $B_{5} \geq 1.396$ From (5.1), $\mathrm{B}_{6} \mathrm{~B}_{7} \mathrm{~B}_{8}<0: 925$ and $\mathrm{B}_{10} \mathrm{~B}_{11} \mathrm{~B}_{12}<0: 104$, so we have $\frac{B_{5}^{3}}{B_{6} B_{7} B_{8}}>2$ and $\frac{B_{9}^{3}}{B_{10} B_{11} B_{12}}>\frac{\left(\varepsilon \mathrm{B}_{5}\right)^{3}}{B_{10} B_{11} B_{12}}>2$ Applying AMGM to the inequality $(1,2,1,4,4)$ we get $\mathrm{B}_{1}+4 \mathrm{~B}_{2}-\frac{2 B_{2}^{2}}{B_{3}}+\mathrm{B}_{4}+4 \mathrm{~B}_{5}+4 \mathrm{~B}_{9}$ $\sqrt{B_{5}^{5} B_{9}^{5} B_{1} B_{2} B_{3} B_{4}}>13$ We find that left side is a decreasing function of $\mathrm{B} 2$ and $\mathrm{B} 9$. So we replace $\mathrm{B} 2$ by 2:0299 and $\mathrm{B}_{9}$ by $\varepsilon_{\mathrm{B}_{5}}$. Now it becomes a decreasing function of $\mathrm{B}_{5}$ and an increasing function of $\mathrm{B}_{1}$ so replacing

$\mathrm{B}_{5}$ by 1.396 and $\mathrm{B}_{1}$ by 2.4273 , we find that above inequality is not true for $1: 522<\mathrm{B}_{3}<1: 9517$ and $1: 426<\mathrm{B}_{4}<1: 646$, giving thereby a contradiction. Hence we must have $\mathrm{B}_{5}<1: 396$.

Claim (x) B3>1:7855

Suppose $B_{3} \leq 1.7855$ We have B4>1:426>each of $\mathrm{B}_{5} ; \mathrm{B}_{6}, \ldots, \mathrm{B}_{12}$, hence the inequality $\left(1 ; 2 ; 9^{*}\right)$ holds. It gives $\phi_{15}=B_{1}+4 B_{2}-\frac{2 B_{2}^{2}}{B_{3}}+9\left(\frac{1}{B_{1} B_{2} B_{3}}\right)^{\frac{1}{9}}>13$ It is easy to check that left side of above inequality is a decreasing function of B2 and an increasing function of $\mathrm{B} 1$ and $\mathrm{B} 3$. So replacing $\mathrm{B}_{1}$ by $2.4273, \mathrm{~B}_{3}$ by 1.7855 and $\mathrm{B}_{2}$ by 2.0299 we get $-15<13$; a contradiction. Hence we have $B_{3}>1: 7855$.

Claim (xi) $B_{2}>2.0733$

Suppose $B_{2} \leq 2.0733$ Wehave $\mathrm{B} 3>1: 7855>$ each of $\mathrm{B}_{4} ; \mathrm{B}_{5}, \ldots, \mathrm{B}_{12}$, hence the inequality $\left(2 ; 10^{*}\right)$ holds. It gives $\phi_{16}=4 B_{1}-\frac{2 B_{1}^{2}}{B_{2}}+10.3\left(\frac{1}{B_{1} B_{2}}\right)^{\frac{1}{10}}>13$ The left side is a decreasing function of $B_{1}$ and an increasing function of $B_{2}$, so replacing $B_{1}$ by $2: 17$ and $B_{2}$ by 2.0733 we get $\phi_{16}<13$ a contradiction.

\section{Claim (xii) B7 $<0: 92$ and $\mathrm{B} 5<1: 38$}

Suppose $B_{7} \geq 0.92$ Here we have $\mathrm{B}_{4} \mathrm{~B}_{5} \mathrm{~B}_{6}<2: 67$ and $\mathrm{B}_{8} \mathrm{~B}_{9} \mathrm{~B}_{10}<0: 295$, so $\frac{B_{3}^{3}}{B_{4} B_{5} B_{6}}>2$ and $\frac{B_{7}^{3}}{B_{8} B_{9} B_{10}}>2$ Also $2 B_{11} \geq 2 \varepsilon B_{7}>B_{12}$ Applying AM-GM to the inequality $(2,4,4,2)$ we get $\phi_{17}=4 B_{1}-\frac{2 B_{1}^{2}}{B_{2}}+4 B_{3}+4 B_{7}-\sqrt{B_{3}^{5} B_{7}^{5} B_{1} B_{2} B_{11} B_{12}}+4 B_{11}-\frac{2 B_{11}^{2}}{B_{12}}>13$ We find that left side is a decreasing function of $\mathrm{B} 1$ and $\mathrm{B} 11$. So we can replace $\mathrm{B} 1$ by 2:17 and $\mathrm{B} 11$ by $\varepsilon \mathrm{B}_{7}$. Then left side becomes a decreasing function of $\mathrm{B}_{7}$ and an increasing function of $\mathrm{B}_{2}$, so can replace $\mathrm{B}_{7}$ by 0.92 and $\mathrm{B}_{2}$ by 2.2254706 to see that $\phi_{17}<13$ for $1: 7855<\mathrm{B}_{3}<1: 9517$ and $0: 3376<\mathrm{B}_{12}<0: 4156$, a contradiction. Hence $B_{7}<0: 92$. Further $B_{5} \leq \frac{3}{2} B_{7}$ gives $B_{5}<1: 38$.

Claim (xiii) B6<1:097

Suppose $B_{6} \geq 1.097$ Here we have B3B4B5 $<4: 44$ and B7B8B9 $<0: 5$, so $\quad \frac{B_{2}^{3}}{B_{3} B_{4} B_{5}}>\frac{(2.0733)^{3}}{4.44}>2$ and $\quad \frac{B_{6}^{3}}{B_{7} B_{8} B_{9}}>2 \quad$ Also $2 B_{10} \geq 2 \varepsilon B_{6}>B_{11}$ Applying AM-GM to the inequality $(1,4,4,2,1)$ we get $\phi_{18}=B_{1}+4 B_{2}+4 B_{6}-\sqrt{B_{2}^{5} B_{6}^{5} B_{1} B_{10} B_{11} B_{12}}+4 B_{10}-\frac{2 B_{10}^{2}}{B_{11}}+B_{12}>13$ We find that left side is a decreasing function of $B_{10}, B_{12}$ and $B_{11}$. So we can replace $B_{10}$ by $\varepsilon \mathrm{B}_{6}$ and $\mathrm{B}_{12}$ by 0.3376 and $\mathrm{B}_{11}$ by $\frac{3 \varepsilon}{4} \mathrm{~B}_{6}$. Then left side becomes a decreasing function of $\mathrm{B}_{6}$, so we can replace $\mathrm{B}_{6}$ by 1.097 to find that $\phi$ ${ }_{18}<13$, for $2: 17<\mathrm{B}_{1}<2: 4273$ and 2:0733 $<\mathrm{B}_{2}<2: 2254706$, a contradiction. Hence we must have $\mathrm{B}_{6}<1: 097$.

Claim (xiv) $\mathrm{B}_{5}>\mathrm{B}_{6}$ and $\frac{B_{1}^{3}}{B_{2} B_{3} B_{4}}<2$

First suppose B5 $\leq$ B6, then B4B5B6<1:646 × 1:0972<1:981 and $\frac{B_{3}^{3}}{B_{4} B_{5} B_{6}}>2$ Also $B_{7} \geq \varepsilon B_{3}>0.83>$ eachof $B_{8}, \ldots, B_{12}$. Hencetheinequality $\left(2 ; 4 ; 6^{*}\right)$ holds, i.e. $4 B_{1}-\frac{2 B_{1}^{2}}{B_{2}}+4 B_{3}-\frac{1}{2} \frac{B_{3}^{4}}{B_{4} B_{5} B_{6}}+6\left(\frac{1}{B l B_{2} B_{3} B_{4} B_{5} B_{6}}\right)^{\frac{1}{6}}>13$ Now the left side is a decreasing function of $B 1$ and $B 3$ as well; also it is an increasing function of $\mathrm{B}_{2}$ and $\mathrm{B}_{4} \mathrm{~B}_{5} \mathrm{~B}_{6}$. But one can check that this inequality is not true for $\mathrm{B}_{1}>2: 17, \mathrm{~B}_{3}>1: 7855, \mathrm{~B}_{2}<2: 2254706$ and $\mathrm{B}_{4} \mathrm{~B}_{5} \mathrm{~B}_{6}<1: 981$, giving thereby a contradiction. Further suppose $\frac{B_{1}^{3}}{B_{2} B_{3} B_{4}} \geq 2$ then as $\mathrm{B} 5>\mathrm{B} 6>1: 019>$ each of $\mathrm{B} 7, \ldots, \mathrm{B} 12$, the inequality ( 4 ; $8^{\star}$ ) holds. Now working as in Case (i) of Claim (viii) we get contradiction for B1 2:17 and B2B3B4<2:2254706 × 1:9517 × 1:646<7:14934.

Claim (xv) B3<1:9 and B1<2:4056

Suppose $B_{3} \geq 1.9$, then for $\mathrm{B}_{4} \mathrm{~B}_{5} \mathrm{~B}_{6}<1: 646 \times 1: 38 \times 1: 097<2: 492$, $\frac{B_{3}^{3}}{B_{4} B_{5} B_{6}}>2 \quad$ Also $\quad \mathrm{B} 7 \geq \varepsilon \quad \mathrm{B} 3>0: 89>$ each of $\mathrm{B}_{8}, \ldots, \mathrm{B}_{12}$. Hence the inequality $\left(2 ; 4 ; 6^{*}\right)$ holds. Now working as in Claim (xiv) we get contradiction for $\mathrm{B}_{1}>2: 17, \mathrm{~B}_{2}<2: 2254706, \mathrm{~B}_{3}>1: 9$ and $\mathrm{B}_{4} \mathrm{~B}_{5} \mathrm{~B}_{6}<2: 492$. So $\mathrm{B}_{3}<1: 9$. Further if $\mathrm{B}_{1} \geq 2: 4056$, then $\frac{B_{1}^{3}}{B_{2} B_{3} B_{4}}>\frac{(2.4056)^{3}}{2.2254706 \times 1.9 \times 1.646}>2$ contradicting Claim (xiv).

Claim (xvi) $\mathrm{B}_{4}<1: 58$ and $\mathrm{B}_{1}<2: 373$

Suppose $B_{4} \geq 1.58$ thenfor $\mathrm{B}_{5} \mathrm{~B}_{6} \mathrm{~B}<1: 38 \times 1: 097 \times 0: 92<1: 393, \frac{B_{4}^{3}}{B_{5} B_{6} B_{7}}>2$ Also $\mathrm{B}_{8} \geq \varepsilon \mathrm{B}_{4}>0: 74>$ each of $\mathrm{B}_{9}, \ldots, \mathrm{B}_{12}$. Hence the inequality $\left(1 ; 2 ; 4 ; 5^{*}\right)$ 
Citation: Kathuria L, Raka M (2015) Refined Estimates on Conjectures of Woods and Minkowski-I. J Appl Computat Math 4: 209. doi:10.4172/21689679.1000209

Page 9 of 10

holds, i.e. $-19=\mathrm{B}_{1}+4 \mathrm{~B}_{2}-\frac{2 B_{2}^{2}}{B_{3}}+4 B_{4}-\frac{1}{2} \frac{B_{4}^{4}}{B_{5} B_{6} B_{7}}+5\left(\frac{1}{B_{1} B_{2} B_{3} B_{4} B_{5} B_{6} B_{7}}\right)^{\frac{1}{5}}>13$

Left side is a decreasing function of $\mathrm{B}_{2}$ and $\mathrm{B}_{4}$.

So we replace $B_{2}$ by 2.0733 and $B_{4}$ by 1.58 . Then it becomes an increasing function of $\mathrm{B}_{1}, \mathrm{~B}_{3}$ and $\mathrm{B}_{5} \mathrm{~B}_{6} \mathrm{~B}_{7}$. So we replace $\mathrm{B}_{1}$ by $2.4056, \mathrm{~B}_{3}$ by 1.9 and $B_{5} B_{6} B_{7}$ by 1.393 to find that $-19<13$, a contradiction. Further if $B_{1} \geq 2: 373$, then $\frac{B_{1}^{3}}{B_{2} B_{3} B_{4}}>2$ contradicting Claim (xiv).

\section{Final Contradiction:}

We have $\mathrm{B}_{3} \mathrm{~B}_{4} \mathrm{~B}<1: 9 \times 1: 58 \times 1: 38<4: 15$. Therefore $\frac{B_{2}^{3}}{B_{3} B_{4} B_{5}}>2$ Also B6 $>1: 019>$ each of $B_{7}, \ldots, B_{12}$. Hence the inequality $\left(1 ; 4 ; 7^{\star}\right)$ holds. Now we get contradiction working as in Case (ii) of Claim (viii).

\subsection{2:17<B12<2:2254706}

Here $B_{1} \geq B_{12}>2.17$ Using Lemma 3 and 4 , we have

$\mathrm{B}^{11}=\left(\mathrm{B}_{1} \mathrm{~B}_{2} \ldots \mathrm{B}_{10} \mathrm{~B}_{12}\right)^{-1}<\left(\frac{3}{64} \varepsilon^{8} \mathrm{~B}_{1}^{10} \mathrm{~B}_{12}\right)^{-1}<1.8223$

Claim (i) Either B11<0:4307 or B11 $>1: 818$

Suppose 0:4307 $\leq \mathrm{B}_{11} \leq 1.818$ The inequality $\left(10^{\star} ; 1 ; 1\right)$ gives $10: 3$ $\left(\frac{1}{B_{11} B_{12}}\right)^{\frac{1}{10}}+B_{11}+B_{12}>13$ which is not true for 0:4307 $\leq \mathrm{B}_{11} \leq 1.818$ and $2: 17<B 12<2: 2254706$. So we must have either $B_{11}<0: 4307$ or $B_{11}>1: 818$.

Claim (ii) B11<0:4307

Suppose $B_{11} \geq 0.4307$ then using Claim(i) we have B11>1:818. Now we have using Lemmas $3 \& 4$,

$B_{2}=\left(\mathrm{B}_{1} \mathrm{~B}_{2} \ldots \mathrm{B}_{12}\right)^{-1}<\left(\frac{1}{16} \varepsilon^{6} \mathrm{~B}_{2}^{8} \mathrm{~B}_{1} \mathrm{~B}_{11} \mathrm{~B}_{12}\right)^{-1}$ This gives $\mathrm{B} 2<1: 777$.

$B_{3}=\left(\mathrm{B}_{1} \mathrm{~B}_{2} \mathrm{~B}_{4} \ldots \mathrm{B}_{12}\right)^{-1}<\left(\frac{3}{64} \varepsilon^{4} \mathrm{~B}_{3}^{7} \mathrm{~B}_{1}^{2} \mathrm{~B}_{11} \mathrm{~B}_{12}\right)^{-1}$ This gives $\mathrm{B} 3<1: 487$

$B_{4}=\left(\mathrm{B}_{1} \mathrm{~B}_{2} \mathrm{~B}_{4} \ldots \mathrm{B}_{12}\right)^{-1}<\left(\frac{1}{16} \varepsilon^{3} \mathrm{~B}_{4}^{6} \mathrm{~B}_{1}^{3} \mathrm{~B}_{11} \mathrm{~B}_{12}\right)^{-1}$ This gives $\mathrm{B} 4<1: 213$.

$B_{6}=\left(\mathrm{B}_{1} \ldots \mathrm{B}_{5} \mathrm{~B}_{7} \ldots \mathrm{B}_{12}\right)^{-1}<\left(\frac{1}{16} \varepsilon^{2} \mathrm{~B}_{6}^{4} \mathrm{~B}_{1}^{5} \mathrm{~B}_{11} \mathrm{~B}_{12}\right)^{-1}$ This gives $\mathrm{B} 6<0: 826$.

$B_{7}=\left(\mathrm{B}_{1} . . \mathrm{B}_{6} \mathrm{~B}_{8} \ldots \mathrm{B}_{12}\right)^{-1}<\left(\frac{3}{64} \varepsilon^{2} \mathrm{~B}_{7}^{3} \mathrm{~B}_{1}^{6} \mathrm{~B}_{11} \mathrm{~B}_{12}\right)^{-1}$ This gives $\mathrm{B} 7<0: 697$.

$B_{8}=\left(\mathrm{B}_{1} . . \mathrm{B}_{7} \mathrm{~B}_{9} \ldots \mathrm{B}_{12}\right)^{-1}<\left(\frac{1}{16} \varepsilon^{3} \mathrm{~B}_{8}^{2} \mathrm{~B}_{1}^{7} \mathrm{~B}_{11} \mathrm{~B}_{12}\right)^{-1}$ This gives $\mathrm{B} 8<0: 559$.

$B_{9}=\left(\mathrm{B}_{1} . . \mathrm{B}_{8} \mathrm{~B}_{10} \mathrm{~B}_{11} \mathrm{~B}_{12}\right)^{-1}<\left(\frac{3}{64} \varepsilon^{3} \mathrm{~B}_{9} \mathrm{~B}_{1}^{7} \mathrm{~B}_{11} \mathrm{~B}_{12}\right)^{-1}$ This gives $\mathrm{B} 9<0: 478$.

$B_{10}=\left(\mathrm{B}_{1} . . \mathrm{B}_{9} \mathrm{~B}_{11} \mathrm{~B}_{12}\right)^{-1}<\left(\frac{1}{16} \varepsilon^{6} \mathrm{~B}_{1}^{9} \mathrm{~B}_{11} \mathrm{~B}_{12}\right)^{-1}<0.359$

Therefore we have $\frac{B_{1}^{3}}{B_{2} B_{3} B_{4}}>2$ and $B_{5} \geq \varepsilon B_{1}>1.01>$ each of $\mathrm{B}_{6}, \ldots, \mathrm{B}_{10}$. So the inequality $\left(4 ; 6^{\star} ; 1 ; 1\right)$ holds, i.e. $4 \mathrm{~B}_{1}-\frac{1}{2} \frac{B_{1}^{4}}{B_{2} B_{3} B_{4}}+6$ $\left(\mathrm{B}_{1} \mathrm{~B}_{2} \mathrm{~B}_{3} \mathrm{~B}_{4} \mathrm{~B}_{11} \mathrm{~B}_{12}\right)^{-1 / 6}+\mathrm{B}_{11}+\mathrm{B}_{12}>13$ Now the left side is an increasing function of $\mathrm{B} 2 \mathrm{~B} 3 \mathrm{~B} 4, \mathrm{~B} 11$ and of $\mathrm{B} 12$ as well. Also it is a decreasing function of $\mathrm{B} 1$. So we replace $\mathrm{B}_{2} \mathrm{~B}_{3} \mathrm{~B}_{4}$ by 1:777 $\times 1: 487 \times 1: 213, \mathrm{~B}_{11}$ by $1.8223, \mathrm{~B}_{12}$ by 2.2254706 and $\mathrm{B}_{1}$ by 2.17 to arrive at a contradiction. Hence we must have $\mathrm{B}_{11}<0: 4307$.

Claim (iii) B10<0:445
Suppose $B_{10} \geq 0.445$ then $2 \mathrm{~B}_{10}>\mathrm{B}_{11}$. So the inequality $\left(9^{*} ; 2 ; 1\right)$ holds, i.e. $\phi_{20}=9\left(\frac{1}{B_{10} B_{11} B_{12}}\right)^{\frac{1}{9}}+4 B_{10}-\frac{2 B_{10}^{2}}{B_{11}}+B_{12}>13 \quad B_{11} \geq \frac{3}{4} \quad \mathrm{~B} 10 \quad$ and B12>2:2254706, the left side is an increasing function of B12 and a decreasing function of $\mathrm{B}_{10}$, so replacing $\mathrm{B}_{12}$ by 2.2254706 and $\mathrm{B}_{10}$ by 0.445 we find that $\phi_{20}<13$, for $34(0: 445)<B_{11}<0: 4307$, a contradiction. Hence we must have $\mathrm{B}_{10}<0: 445$.

Using Lemmas 3 and 4 we have:

$$
\begin{aligned}
& B_{9} \leq \frac{4}{3} B_{10}<0.594, B_{8} \leq \frac{3}{2} B_{10}<0.67, B_{7} \leq 0.89 \\
& B_{6} \leq \frac{B_{10}}{\varepsilon}<0.9494, B_{5} \leq \frac{4}{3} \frac{B_{10}}{\varepsilon}<1.266, B_{4} \leq \frac{3}{2} \frac{B_{10}}{\varepsilon}<1.4242 \\
& B_{3} \leq \frac{2 B_{10}}{\varepsilon}<1.899, B_{2} \leq \frac{B_{10}}{(\varepsilon)^{2}}<2.0255
\end{aligned}
$$

Claim (iv) B3 $<1: 62$

Suppose $\quad B_{3} \geq 1.62$ From (5.2), we have $B 4 B 5 B 6<1: 712$ and $\quad \mathrm{B} 8 \mathrm{~B} 9 \mathrm{~B} 10<0: 178, \quad$ so $\quad \frac{B_{3}^{3}}{B_{4} B_{5} B_{6}}>2 \quad$ and $\quad \frac{B_{7}^{3}}{B_{8} B_{9} B_{10}}>2$ Applying AM-GM to the inequality $(2,4,4,1,1)$ we get $\phi_{21}=4 B_{1}-\frac{2 B_{1}^{2}}{B_{2}}+4 B_{3}+4 B_{7}-\sqrt{B_{3}^{5} B_{7}^{5} B_{1} B_{2} B_{11} B_{12}}+B_{11}+B_{12}>13$ We find that left side is a decreasing function of $B_{1}, B_{7}$ and $B_{11}$. So we can replace $B_{1}$ by $B_{12}$, $\mathrm{B}_{7}$ by $\varepsilon \mathrm{B}_{3}$ and $\mathrm{B}_{11}$ by $\varepsilon^{2} \mathrm{~B}_{3}$. Then it becomes a decreasing function of $B_{3}$, so replacing $B_{3}$ by 1.62 we find that $\phi 21<13$; for $1: 6275<B_{2}<2: 0255$ and 2:17 $<\mathrm{B}_{12}<2: 2254706$, a contradiction. Hence we must have $\mathrm{B}_{3}<1: 62$.

Claim (v) B12>2:196

Suppose $B_{12} \leq 2.196$ From (5.2), we have $B_{2} B_{3} B_{4}<4: 674$ and $\frac{B_{1}^{3}}{B_{2} B_{3} B_{4}}>2$ Also $B_{5} \geq \varepsilon B_{1}>1.01>$ each of $\mathrm{B} 6, \ldots$, B11. Therefore the inequality $\left(4 ; 7^{*} ; 1\right)$ holds, i.e. $\phi_{22}$ $\phi_{22}=4 B_{1}-\frac{1}{2} \frac{B_{1}^{4}}{B_{2} B_{3} B_{4}}+7\left(\mathrm{~B}_{1} \mathrm{~B}_{2} \mathrm{~B}_{3} \mathrm{~B}_{4} \mathrm{~B}_{12}\right)^{-1 / 7}+B_{12}>13 \quad$ Left side is an increasing function of $\mathrm{B} 2 \mathrm{~B} 3 \mathrm{~B} 4$ and of $\mathrm{B}_{12}$ as well. Also it is a decreasing function of $B_{1}$. So we can replace $B_{2} B_{3} B_{4}$ by $4.674, B_{12}$ by 2.196 and $B_{1}$ by 2.17 to get $\phi 22<13$, a contradiction. Hence we must have $B_{12}>2: 196$.

\section{Final Contradiction}

Now we have $B_{1} \geq B_{12}>2: 196$. We proceed as in Claim(v) and use $\left(4 ; 7^{\star} ; 1\right)$. Here we replace $\mathrm{B}_{2} \mathrm{~B}_{3} \mathrm{~B}_{4}$ by $4.674, \mathrm{~B}_{12}$ by 2.2254706 and $\mathrm{B}_{1}$ by 2.196 to get $\phi_{22}<13$, a contradiction.

\section{References}

1. Bambah RP, Dumir VC, Hans-Gill RJ (2000) Non-homogeneous prob-lems: Conjectures of Minkowski and Watson, Number Theory, Trends in Mathematics, Birkhauser Verlag, Basel 15-41.

2. Birch BJ, Swinnerton-Dyer HPF (1956) On the inhomogeneous min-imum of the product of $n$ linear forms, Mathematika 3: 25-39.

3. Blichfeldt HF (1934) The minimum values of positive quadratic forms in six seven and eight variables, Math Z 39: 1-15.

4. Cebotarev N (1940) Beweis des Minkowski'schen Satzes uber lineare inhomogene Formen, Vierteljschr. Naturforsch. Ges. Zurich, 85 Beiblatt 27-30.

5. Cohn H, Elkies N (2003) New upper bounds on sphere packings, I. Ann of Math 157: 689-714.

6. Cohn H, Kumar A (2004) The densest lattice in twenty-four dimensions Electron. Res Announc Amer Math Soc 10: 58-67. 
Citation: Kathuria L, Raka M (2015) Refined Estimates on Conjectures of Woods and Minkowski-I. J Appl Computat Math 4: 209. doi:10.4172/21689679.1000209

Page 10 of 10

7. Conway JH, Sloane NJA (1993) Sphere packings, Lattices and groups, Springer-Verlag, Second edition, New York.

8. Gruber P (2007) Convex and discrete geometry, Springer Grundlehren Series 336.

9. Gruber P, Lekkerkerker CG (1987) Geometry of Numbers, Second Edi-tion, North Holland, 37.

10. Hans-Gill RJ, Raka M, Sehmi R, Sucheta (2009) A uni ed simple proof of Woods' conjecture for $n$ 6, J Number Theory 129: 1000-1010.

11. Hans-Gill RJ, Raka M, Sehmi R (2009) On conjectures of Minkowski and Woods for $\mathrm{n}=7$, J Number Theory 129: 1011-1033.

12. Hans-Gill RJ, Raka M, Sehmi R (2010) Estimates On Con-jectures of Minkowski and Woods, Indian JI Pure Appl Math 41: 595-606.

13. Hans-Gill RJ, Raka M, Sehmi R (2011) On Conjectures of Minkowski and Woods for $\mathrm{n}=8$, Acta Arithmetica 147: 337-385.

14. Hans-Gill RJ, Raka M, Sehmi R (2011) Estimates On Con-jectures of Minkowsk and Woods II, Indian JI. Pure Appl. Math. 42: 307-333.

15. Il'in IV (1986) A remark on an estimate in the inhomogeneous Minkowski conjecture for small dimensions,) 90, Petrozavodsk. Gos. Univ., Petrozavodsk 24-30.

16. IV (1991) Chebotarev estimates in the inhomogeneous Minkowski con-jecture for small dimensions, Algebraic systems, Ivanov. Gos. Univ, Ivanovo 115-125.

17. Kathuria L, Raka M (2014) On Conjectures of Minkowski and Woods for $n=9$.

18. Kathuria L, Raka M (2011) Refined Estimates on Conjectures of Woods and Minkowski-II, To be Submitted.

19. Kathuria L, Raka M (2014) Generalization of a result of Birch and SwinnertonDyer, To be Submitted.

20. Korkine A, Zolotare G (1877) Sur les formes quadratiques, Math. Ann. 366 389; Sur les formes quadratiques positives. Math Ann 11: 242-292.

21. McMullen CT (2005) Minkowski's conjecture, well rounded lattices and topological dimension. J Amer Math Soc 18: 711-734.

22. Mordell LJ (1960) Tschebotare's Theorem on the product of Non-homogeneous Linear Forms (II). J London Math Soc 35: 91-97.

23. Pendavingh RA, Van Zwam SHM (2007) New Korkine-Zolotarev in-equalities SIAM J Optim 18: 364-378.

24. Woods AC (1965) The densest double lattice packing of four spheres. Mathematika 12: 138-142.

25. Woods AC (1965) Lattice coverings of ve space by spheres. Mathematika 12 143-150.

26. Woods AC (1972) Covering six space with spheres. J Number Theory 4: 157 180 